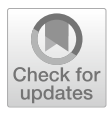

Cite as

Nano-Micro Lett.

(2021) 13:116

Received: 4 February 2021

Accepted: 22 March 2021

Published online: 30 April 2021

(C) The Author(s) 2021

\section{Enhanced Reversible Zinc Ion Intercalation in Deficient Ammonium Vanadate for High-Performance Aqueous Zinc-Ion Battery}

Quan Zong ${ }^{1,2}$, Wei Du ${ }^{2}$, Chaofeng Liu ${ }^{1}$, Hui Yang ${ }^{2}$, Qilong Zhang ${ }^{2}{ }^{凶}$, Zheng Zhou ${ }^{2}$, Muhammad Atif ${ }^{3,4}$, Mohamad Alsalhi ${ }^{3,4}$, Guozhong $\mathrm{Cao}^{1}$ 凶

\title{
HIGHLIGHTS
}

- The partial removal of ammonium cations from ammonium vanadate results in anexpanded interplanar space.

- The deficient ammonium vanadate exhibits highly reversible redox reaction.

- Ex situ characterizations suggest the reversible $\mathrm{Zn}_{3} \mathrm{~V}_{2} \mathrm{O}_{7}(\mathrm{OH})_{2} \cdot 2 \mathrm{H}_{2}$ Oformation/decomposition in deficient ammonium vanadate duringcharge/discharge processes.

\begin{abstract}
Ammonium vanadate with bronze structure $\left(\mathrm{NH}_{4} \mathrm{~V}_{4} \mathrm{O}_{10}\right)$ is a promising cathode material for zinc-ion batteries due to its high specific capacity and low cost. However, the extraction of $\mathrm{NH}_{4}^{+}$at a high voltage during charge/discharge processes leads to irreversible reaction and structure degradation. In this work, partial $\mathrm{NH}_{4}^{+}$ions were preremoved from $\mathrm{NH}_{4} \mathrm{~V}_{4} \mathrm{O}_{10}$ through heat treatment; $\mathrm{NH}_{4} \mathrm{~V}_{4} \mathrm{O}_{10}$ nanosheets were directly grown on carbon cloth through hydrothermal method. Deficient $\mathrm{NH}_{4} \mathrm{~V}_{4} \mathrm{O}_{10}$ (denoted as $\mathrm{NVO}$ ), with enlarged interlayer spacing, facilitated fast zinc ions transport and high storage capacity and ensured the highly reversible electrochemical reaction and the good stability of layered structure. The NVO nanosheets delivered a high specific capacity of $457 \mathrm{mAh} \mathrm{g}^{-1}$ at a current density of $100 \mathrm{~mA} \mathrm{~g}^{-1}$ and a capacity retention of $81 \%$ over 1000 cycles at $2 \mathrm{~A} \mathrm{~g}^{-1}$. The initial Coulombic
\end{abstract}

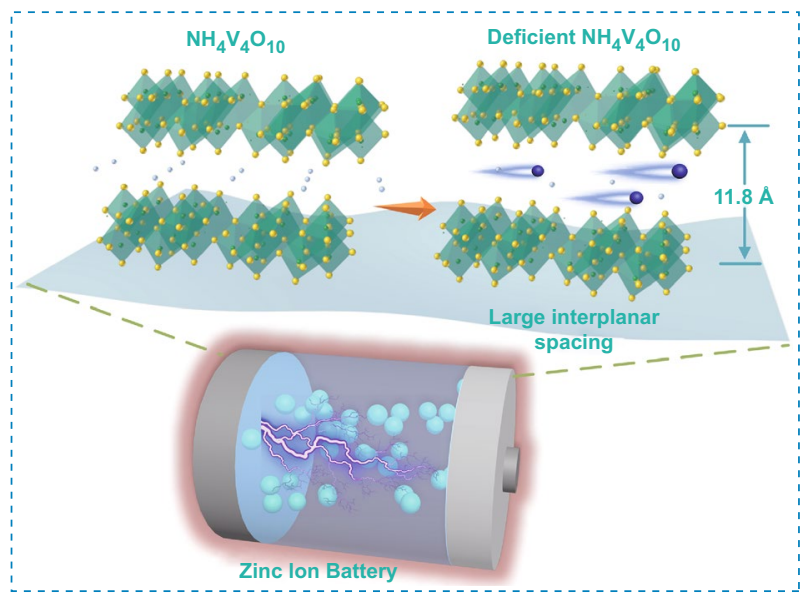
efficiency of $\mathrm{NVO}$ could reach up to $97 \%$ compared to $85 \%$ of $\mathrm{NH}_{4} \mathrm{~V}_{4} \mathrm{O}_{10}$ and maintain almost $100 \%$ during cycling, indicating the high reaction reversibility in NVO electrode.

KEYWORDS Deficient ammonium vanadate; Large interlayer spacing; Reversible redox reaction; Electrochemical mechanism

Qilong Zhang, mse237@zju.edu.cn; Guozhong Cao, gzcao@uw.edu

1 Department of Materials Science and Engineering, University of Washington, Seattle, WA 98195, USA

2 School of Materials Science and Engineering, State Key Lab Silicon Mat, Zhejiang University, Hangzhou 310027, People's Republic of China

3 Research Chair On Laser Diagnosis of Cancers, Department of Physics and Astronomy, College of Science, King Saud University, Riyadh 11451, Saudi Arabia

4 Department of Physics and Astronomy, College of Science, King Saud University, Riyadh 11451, Saudi Arabia 


\section{Introduction}

The global energy crisis and environmental issues continuously drive the development of renewable energy sources such as solar, wind and tidal energy [1,2]. Electrical energy storage (EES) systems are vital to enable and guarantee the reliability and scalability of these renewable energies $[3,4]$. Among various EES systems, lithium-ion batteries (LIBs) have been widely employed in the smart electronics and electric vehicles owing to their high energy density and the long-term lifespan [5-7]. Nevertheless, the safety issues, high cost, environmental concerns, as well as limited lithium resources have strongly restricted their large-scale and sustainable applications $[8,9]$. Recently, a variety of aqueous batteries based on alkali metal cations $\left(\mathrm{Li}^{+}, \mathrm{Na}^{+}\right.$, and $\left.\mathrm{K}^{+}\right)$ and multivalent charge carriers $\left(\mathrm{Mg}^{2+}, \mathrm{Ca}^{2+}, \mathrm{Zn}^{2+}\right.$, and $\left.\mathrm{Al}^{3+}\right)$ have attracted great attention [10-14]. Aqueous zinc-ion batteries (ZIBs) are increasingly developed owing to their low cost, excellent safety, relatively high theoretical capacity $\left(820 \mathrm{mAh} \mathrm{g}^{-1}\right)$ and low redox potential $(-0.76 \mathrm{~V} v s$. the standard hydrogen electrode) [15-17]. To date, a lot of attention has been paid on the cathode materials for ZIBs including manganese oxides [18-20], vanadium-based compounds [21-25], Prussian blue and its analogs [26], transition metal dichalcogenides [27, 28], and polymers [29]. However, some disadvantages seriously hinder the practical application of these materials, such as irreversible phase transition of manganese oxides, low specific capacity of Prussian blue and its analogs $\left(<100 \mathrm{mAh} \mathrm{g}^{-1}\right)$, and low electrical conductivity of transition metal dichalcogenides [30-32].

Layered vanadate-based compounds have become the most competitive cathode materials for ZIBs owing to the multivalence state of vanadium ions from $5+$ to $3+$ and tunable layer structure with sufficient active sites for $\mathrm{Zn}$-ion transport and accommodation, such as $\mathrm{V}_{2} \mathrm{O}_{5}$ and $\mathrm{VO}_{2}$ [33-35]. However, $\mathrm{V}_{2} \mathrm{O}_{5}$ suffers from the sluggish kinetics due to the narrow interplanar spacing $(4.4 \AA)$ and poor electrical conductivity $\left(10^{-2}-10^{-3} \mathrm{~S} \mathrm{~cm}^{-1}\right)[36,37]$. The interplanar spacing of layered materials is critical to the electrochemical properties of electrodes [38-40]. To modify the reaction kinetics of $\mathrm{V}_{2} \mathrm{O}_{5}$, ions or molecules have been introduced into the interlayers, such as $\mathrm{Na}^{+}$[41], $\mathrm{K}^{+}$[42], $\mathrm{Cu}^{2+}$ [43], $\mathrm{H}_{2} \mathrm{O}$ [44], and PANI [45]. These ions or molecules acting as "pillars" not only accelerate zinc ions insertion/extraction but also stabilize the layered host structure. Recently, layered ammonium vanadate has attracted great attention due to the relatively large ionic size of $\mathrm{NH}_{4}^{+}$in the layers and small molecular weight, providing high specific capacity [46, 47]. Various ammonium vanadates have been studied as cathode materials for ZIBs, including $\left(\mathrm{NH}_{4}\right)_{2} \mathrm{~V}_{6} \mathrm{O}_{16} \cdot 1.5 \mathrm{H}_{2} \mathrm{O}$ [48], $\left(\mathrm{NH}_{4}\right)_{0.5} \mathrm{~V}_{2} \mathrm{O}_{5}$ [49], $\mathrm{NH}_{4} \mathrm{~V}_{4} \mathrm{O}_{10}$ [50], and $\left(\mathrm{NH}_{4}\right)_{2} \mathrm{~V}_{4} \mathrm{O}_{9}$ [51]. Tang et al. investigated the electrochemical performances of $\mathrm{NH}_{4} \mathrm{~V}_{4} \mathrm{O}_{10}$, $\mathrm{NH}_{4} \mathrm{~V}_{3} \mathrm{O}_{8}$, and $\left(\mathrm{NH}_{4}\right)_{2} \mathrm{~V}_{3} \mathrm{O}_{8}$ with different interplanar spacing as the cathodes for ZIBs [52]. Among these ammonium vanadates, $\mathrm{NH}_{4} \mathrm{~V}_{4} \mathrm{O}_{10}$ with the largest interplanar spacing of $9.8 \AA$ shows the best electrochemical performance due to abundant accessible sites for reversible $\mathrm{Zn}^{2+}$ intercalation/ deintercalation. The results demonstrate that the interplanar spacing and vanadium in multiple oxidation states play an important role on the performance improvements of ammonium vanadates cathode materials. However, ammonium vanadates often suffer from structural degradation due to the irreversible extraction of ammonium ions during the cycling test $[53,54]$. These ammonium ions either enter the electrolyte to affect the PH which could degrade electrochemical properties or release toxic ammonia gas which possibly causes the safety problems. And too many ammonium ions in the interlayer could restrict the insertion of zinc ions due to the large electrostatic interactions. The impacts of preremoving ammonium ions from the ammonium vanadates have not been explored in the ZIBs yet.

In this work, we prepared 2D NVO nanosheets through heat treatment of $\mathrm{NH}_{4} \mathrm{~V}_{4} \mathrm{O}_{10}$ nanosheets grown on carbon cloth in air at a low temperature $\left(300{ }^{\circ} \mathrm{C}\right)$. After the heat treatment, the interplanar spacing is enlarged and the ions transfer pathways are increased due to the loss of most $\mathrm{NH}_{4}^{+}$ ions, which is beneficial for rapid $\mathrm{Zn}$-ion intercalation/deintercalation. The layered structure of NVO remains to be stable and the NVO electrode exhibits high reaction reversibility because the deammoniation from the interplanar spacing is effectively prevented, contributing to a long-life span. The electrochemical mechanism in NVO, involving the process of ions intercalation/deintercalation, has been elaborated.

\section{Experimental}

\subsection{Synthesis of NVO Nanosheets}

All chemical reagents were used without any further purification. Prior to the synthesis, a piece of carbon cloth $(1 \times 2$ 
$\mathrm{cm}^{2}$ ) was treated by sonication in $3 \mathrm{M} \mathrm{HCl}$ solution for $30 \mathrm{~min}$, followed by sonication in acetone, deionized (DI) water, and absolute ethanol sequentially for $30 \mathrm{~min}$ each, and dried at $60{ }^{\circ} \mathrm{C}$ under vacuum for $12 \mathrm{~h}$. The $\mathrm{NH}_{4} \mathrm{~V}_{4} \mathrm{O}_{10}$ nanosheets were fabricated through a facile hydrothermal reaction. $4 \mathrm{mmol}$ of $\mathrm{NH}_{4} \mathrm{VO}_{3}(98 \%$, Fisher Scientific) and $4.8 \mathrm{mmol}$ of $\mathrm{H}_{2} \mathrm{C}_{2} \mathrm{O}_{4} \cdot 2 \mathrm{H}_{2} \mathrm{O}$ (98\%, Fisher Scientific) were added into $80 \mathrm{~mL}$ DI water and kept stirring for $30 \mathrm{~min}$. The mixture was transferred to a $100 \mathrm{~mL}$-Teflon-lined stainless-steel autoclave, and then a piece of carbon cloth protected by Polytetrafluoroethylene tape was immersed into the reaction solution. The autoclave was sealed and maintained at $180{ }^{\circ} \mathrm{C}$ for $6 \mathrm{~h}$. After cooling to ambient temperature naturally, the carbon cloth was carefully taken out and rinsed by ethanol and deionized water several times and then dried at $60{ }^{\circ} \mathrm{C}$ under vacuum for $12 \mathrm{~h}$. The $\mathrm{NVO}$ nanosheets were obtained by annealing $\mathrm{NH}_{4} \mathrm{~V}_{4} \mathrm{O}_{10}$ nanosheets at $300{ }^{\circ} \mathrm{C}$ in air for $2 \mathrm{~h}$ with the heating speed of $5{ }^{\circ} \mathrm{C} \mathrm{min}{ }^{-1}$. For comparison, the $\mathrm{NH}_{4} \mathrm{~V}_{4} \mathrm{O}_{10}$ nanosheets were annealed at $400{ }^{\circ} \mathrm{C}$ in air for $2 \mathrm{~h}$ with the same heating speed to prepare $\mathrm{V}_{2} \mathrm{O}_{5}$ nanosheets. The mass load of $\mathrm{NH}_{4} \mathrm{~V}_{4} \mathrm{O}_{10}$, NVO and $\mathrm{V}_{2} \mathrm{O}_{5}$ nanosheets was about $0.7,0.65$ and $0.5 \mathrm{mg} \mathrm{cm}^{-2}$, respectively.

\subsection{Material Characterizations}

The phase of the sample was identified by a Bruker X-ray diffractometer (XRD, D8 Discover with I $\mu$ S 2-D detection system) at an accelerating voltage of $50 \mathrm{kV}$ and a working current of $1000 \mu \mathrm{A}$. Thermogravimetric analysis (TGA) was conducted using a TGA5500 to analyze the thermal stability of the sample within $30-600{ }^{\circ} \mathrm{C}$. Raman spectra were recorded on a Horiba Scientific LabRAM HR Evolution with a laser excitation sources of $514 \mathrm{~nm}$. Fourier transform infrared spectroscopy (FTIR) pattern was collected on Thermo Fisher Nicolet iS5 from 4000 to $400 \mathrm{~cm}^{-1}$ using the ATR technique. The morphologies and structures of the materials were observed using scanning electron microscopy (SEM, SU-8010) and transmission electron microscopy (TEM, Tecnai G2 F20) equipped with an energy-dispersive X-ray spectrometer (EDS) operated at $200 \mathrm{kV}$. X-ray photoelectron spectroscopy (XPS) technique was carried out on Thermo Scientific K-Alpha with an $\mathrm{Al} \mathrm{K} \alpha$ radiation $(1486.6 \mathrm{eV})$ to determine the valent state of elements.

\subsection{Electrochemical Characterizations}

Electrochemical performance was tested using CR2032 cointype cells, which were assembled by binder-free nanosheets as the cathode, $\mathrm{Zn}$ metal as the anode $(0.15-0.25 \mathrm{~mm}$ thick), $80 \mu \mathrm{L}$ of $3 \mathrm{M}$ zinc trifluoromethanesulfonate (98\%, $\left.\mathrm{Zn}\left(\mathrm{CF}_{3} \mathrm{SO}_{3}\right)_{2}\right)$ aqueous solution as electrolyte and a glass fiber filter (Whatman, Grade GF/A) as the separator in an air atmosphere. Cyclic voltammetry (CV) in a voltage window of 0.2-1.6 V and electrochemical impedance spectroscopy (EIS) in the frequency range from $0.01 \mathrm{~Hz}$ to $100 \mathrm{kHz}$ were tested on a Solartron electrochemical station (SI 1287) coupled with an electrochemical impedance spectroscopy system (EIS, SI 1260). The galvanostatic charge-discharge was obtained on a Neware tester (CT-4008). The galvanostatic intermittent titration technique (GITT) was applied to analyze the reaction and diffusion kinetics at a current density of $50 \mathrm{~mA} \mathrm{~g}^{-1}$ and a charge/discharge time and interval of $10 \mathrm{~min}$ for each step.

\section{Results and Discussion}

\subsection{Phase and Structural Characterizations}

XRD patterns of $\mathrm{NH}_{4} \mathrm{~V}_{4} \mathrm{O}_{10}$ and $\mathrm{NVO}$ are compared in Fig. 1a, $\mathrm{NH}_{4} \mathrm{~V}_{4} \mathrm{O}_{10}$ is well indexed to the standard pattern (JCPDS No. 31-0075), belonging to space group of $\mathrm{C} 2 / \mathrm{m}$ with the lattice parameters, $a=11.568 \AA, b=3.652 \AA$, $\mathrm{c}=9.815 \AA$, and $\beta=100.09^{\circ}$. The strong (001) peak located at $8.84^{\circ}$ corresponds to a lattice spacing of $10.0 \AA$, which is similar to the reported $9.8 \AA$ [54]. After annealing at $300{ }^{\circ} \mathrm{C}$ in an air atmosphere, the (001) peak in NVO moving to $7.46^{\circ}$ suggests a large lattice spacing of $11.8 \AA$. In addition, new weak peaks assigned to $\mathrm{V}_{2} \mathrm{O}_{5}$ can be observed in this sample as shown in the enlarged patterns, which can be attributed to uneven heat transfer (Fig. S1). The little $\mathrm{V}_{2} \mathrm{O}_{5}$ almost has no influence on the electrochemical properties of NVO and it will be discussed later. After further annealing in air at $400^{\circ} \mathrm{C}$, the sample shows good crystallinity of orthorhombic $\alpha-\mathrm{V}_{2} \mathrm{O}_{5}$ with the (001) interlayer spacing decreasing to $4.4 \AA$ (Fig. S1). This process can be further confirmed according to TGA curve as shown in Fig. 1b. The weight loss in the first step (before $\sim 105{ }^{\circ} \mathrm{C}$ ) and second step $\left(105 \sim 260{ }^{\circ} \mathrm{C}\right.$ ) originate from the removal of physically absorbed water and 

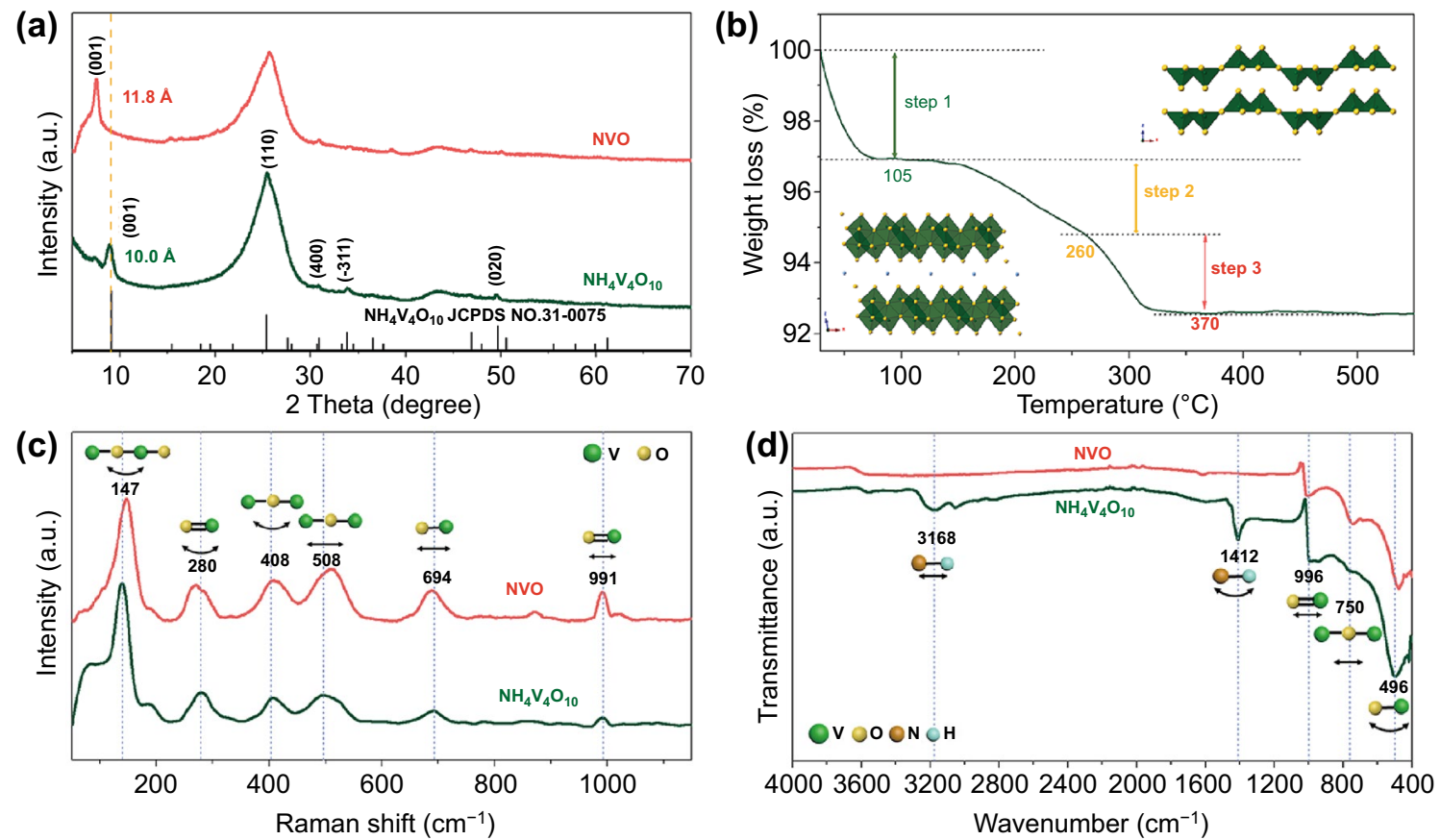

Fig. 1 Phase and structural characterization of $\mathrm{NH}_{4} \mathrm{~V}_{4} \mathrm{O}_{10}$ and NVO. a XRD patterns. The (001) peak in NVO shifts toward a low angle, indicating a large interlayer spacing. b TGA analysis of $\mathrm{NH}_{4} \mathrm{~V}_{4} \mathrm{O}_{10}$. The inset is the crystal structures of bi-layered $\mathrm{NH}_{4} \mathrm{~V}_{4} \mathrm{O}_{10}$ and single layered $\mathrm{V}_{2} \mathrm{O}_{5}$. c Raman and d FTIR spectra, the similar spectra indicate similar VO framework in two samples while the peak changes originate from the loss of $\mathrm{NH}_{4}^{+}$

crystal water, respectively. The formula of the $\mathrm{NH}_{4} \mathrm{~V}_{4} \mathrm{O}_{10}$ sample with crystal water should be $\mathrm{NH}_{4} \mathrm{~V}_{4} \mathrm{O}_{10} \cdot 0.49 \mathrm{H}_{2} \mathrm{O}$. In the third step, the weight loss after $\sim 260^{\circ} \mathrm{C}$ is caused by the release of $\mathrm{NH}_{3}$. The $\mathrm{NVO}$ sample acquired via heat treatment at $300{ }^{\circ} \mathrm{C}$ has lost many $\mathrm{NH}_{4}^{+}$ions from $\mathrm{TG}$ analysis. From the TG results, the formula of the NVO sample can be calculated as $\left(\mathrm{NH}_{4}\right)_{0.55} \mathrm{~V}_{4} \mathrm{O}_{10}$. The expanded interplanar spacing in NVO is probably attributed to the weakened interaction of $\mathrm{NH}_{4}^{+}$with oxygen anion and the enlarged repelling forces between oxygen anions in the layers which could be analyzed from the crystal structure in Fig. 1b. The monoclinic $\mathrm{NH}_{4} \mathrm{~V}_{4} \mathrm{O}_{10}$ consists of distorted $\mathrm{VO}_{6}$ octahedra shared edges, forming a stable bi-layered structure with the inserted $\mathrm{NH}_{4}^{+}$ions in the interlayers [53]. The single-connected oxygen atoms in the layers can induce strong interactions with $\mathrm{NH}_{4}^{+}$ions. With the loss of $\mathrm{NH}_{4}^{+}$ions, the weakened interaction and enlarged repulsive force can lead to an expanded interlayer spacing. The phase transition from $\mathrm{NH}_{4} \mathrm{~V}_{4} \mathrm{O}_{10}$ to $\mathrm{V}_{2} \mathrm{O}_{5}$ is attributed to the extraction of cation $\mathrm{NH}_{4}^{+}$completely at a higher temperature, leading to rearrangement of the bilayered structure. The layer-structured $\mathrm{V}_{2} \mathrm{O}_{5}$ is formed by stacking the single layer of distorted $\mathrm{VO}_{5}$ square pyramids shared corners or edges by van der Waals interactions [55].

The Raman spectra of $\mathrm{NH}_{4} \mathrm{~V}_{4} \mathrm{O}_{10}$ and $\mathrm{NVO}$ in Fig. 1c are approximate to the character of vanadium pentoxide, indicating the similar VO framework with vanadium pentoxide [47]. The similar spectra suggest that the structure has not much change after heat treatment. The peak at $147 \mathrm{~cm}^{-1}$ in NVO is attributed to the bending vibration of $-\mathrm{V}-\mathrm{O}-\mathrm{V}-\mathrm{O}-$ chains and exhibits a long-range order [54]. The $\mathrm{V}=\mathrm{O}$ bending mode appears at $280 \mathrm{~cm}^{-1}$ and a red shift in $\mathrm{NVO}$ means the elongation of $\mathrm{V}=\mathrm{O}$ along the c-direction, which is consistent with the expanded interplanar spacing [21]. The bands at 408 and $508 \mathrm{~cm}^{-1}$ could be assigned to V-O-V banding and stretching mode, respectively [56]. The peaks located at 147,408 , and $508 \mathrm{~cm}^{-1}$ take blue shift compared to $\mathrm{NH}_{4} \mathrm{~V}_{4} \mathrm{O}_{10}$ suggests the strong interaction between $\mathrm{V}$ and $\mathrm{O}$ because of the higher oxidation state of $\mathrm{V}$ after heat treatment. The band at $694 \mathrm{~cm}^{-1}$ is owing to the coordination of vanadium atoms with three oxygen atoms [57]. The band at $991 \mathrm{~cm}^{-1}$ is assigned to $\mathrm{V}=\mathrm{O}$ stretching of distorted octahedra. In the FTIR spectra (Fig. 1d), the peak 
at $496 \mathrm{~cm}^{-1}$ originates from the bending vibration of the $\mathrm{V}-\mathrm{O}$ bonds. The band at $750 \mathrm{~cm}^{-1}$ is due to antisymmetric stretches of the $\mathrm{V}-\mathrm{O}-\mathrm{V}$ bridges from $\mathrm{V}^{4+}$ and $\mathrm{V}^{5+}$ ions. The peak becomes strong in NVO, indicating the $\mathrm{V}-\mathrm{O}$ bond becomes strong because a fraction of $\mathrm{V}^{4+}$ is oxidized to $\mathrm{V}^{5+}$ [58]. The absorption centered around $996 \mathrm{~cm}^{-1}$ is assigned to the stretching mode of $\mathrm{V}=\mathrm{O}$. The distorted octahedral structure in $\mathrm{NH}_{4} \mathrm{~V}_{4} \mathrm{O}_{10}$ results in the splitting band of $\mathrm{V}=\mathrm{O}$ stretching. The merge of bands takes places due to the loss of ammonium cations in NVO. The peaks at around 1412 and $3168 \mathrm{~cm}^{-1}$ in $\mathrm{NH}_{4} \mathrm{~V}_{4} \mathrm{O}_{10}$ correspond to the bending and stretching modes of $\mathrm{N}-\mathrm{H}$, respectively, confirming the presence of $\mathrm{NH}_{4}^{+}$[59]. The peak intensity became weak in NVO because of few $\mathrm{NH}_{4}^{+}$ions between vanadium oxide layers [60].

SEM images in Fig. 2a, b show that the ultrathin NVO nanosheets are grown on the activated carbon cloth uniformly. The hydrophilic surface of activated carbon cloth is suitable for the uniform growth of nanosheets (Fig. S2). The nanosheets almost maintain the original morphology after annealing in $300{ }^{\circ} \mathrm{C}$ compared to the pristine $\mathrm{NH}_{4} \mathrm{~V}_{4} \mathrm{O}_{10}$ (Fig. S3). TEM images (Fig. 2c, d) display the ultrathin nanosheets with a lattice spacing of $0.194 \mathrm{~nm}$, which corresponds to the spacing of (403) plane of $\mathrm{NH}_{4} \mathrm{~V}_{4} \mathrm{O}_{10}$. EDS mapping in Fig. 2e reveals the homogeneous distribution of $\mathrm{N}, \mathrm{V}$, and $\mathrm{O}$ elements in NVO nanosheets. The trace amount of $\mathrm{N}$ element suggests the loss of many ammonium ions between the layers. The high resolution XPS spectrum is used to analyze the valence state of $\mathrm{V}$ in two electrodes shown in Figs. $2 \mathrm{f}$ and S3. For NVO, the peaks at $517.4 \mathrm{ad}$ $516.0 \mathrm{eV}$ are assigned to the $\mathrm{V} 2 \mathrm{p}_{3 / 2}$ electrons of $\mathrm{V}^{5+}$ and $\mathrm{V}^{4+}$, respectively $[61,62]$. The ratio of $\mathrm{V}^{5+} / \mathrm{V}^{4+}$ can be calculated by the integration areas of the fitted peak areas. The $\mathrm{V}^{5+}$ ratio of $60.4 \%$ in NVO is higher than that of $\mathrm{NH}_{4} \mathrm{~V}_{4} \mathrm{O}_{10}$ $(51.6 \%)$ because of the oxidation of $\mathrm{V}^{4+}$ after the heat treatment in air.

\subsection{Electrochemical Reaction Kinetics}

The first cycle of $\mathrm{CV}$ curves at $0.1 \mathrm{mV} \mathrm{s}^{-1}$ of $\mathrm{NH}_{4} \mathrm{~V}_{4} \mathrm{O}_{10}$ and NVO is shown in Fig. 3a, and these multiple redox peaks originate from the inequivalent active sites resulting from the inequivalent vanadium cations, leading to a multistep insertion/extraction of zinc ions into interlayer
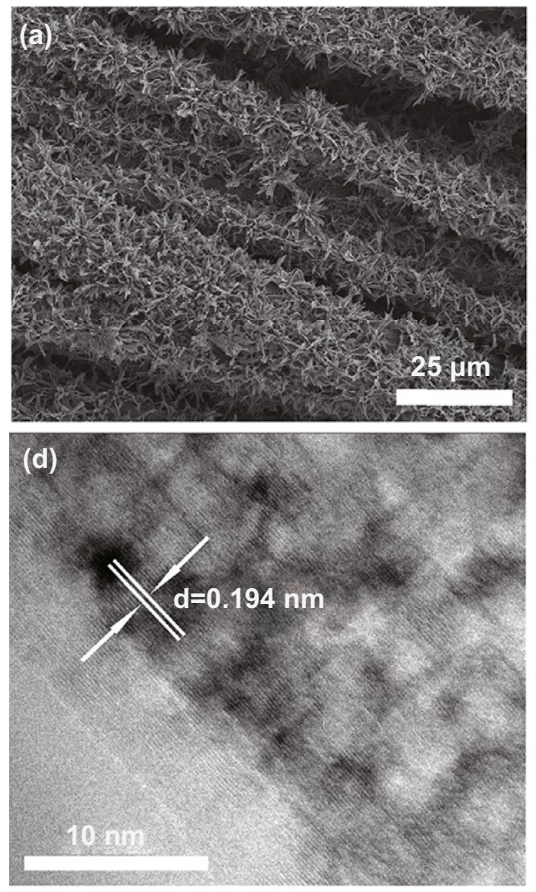
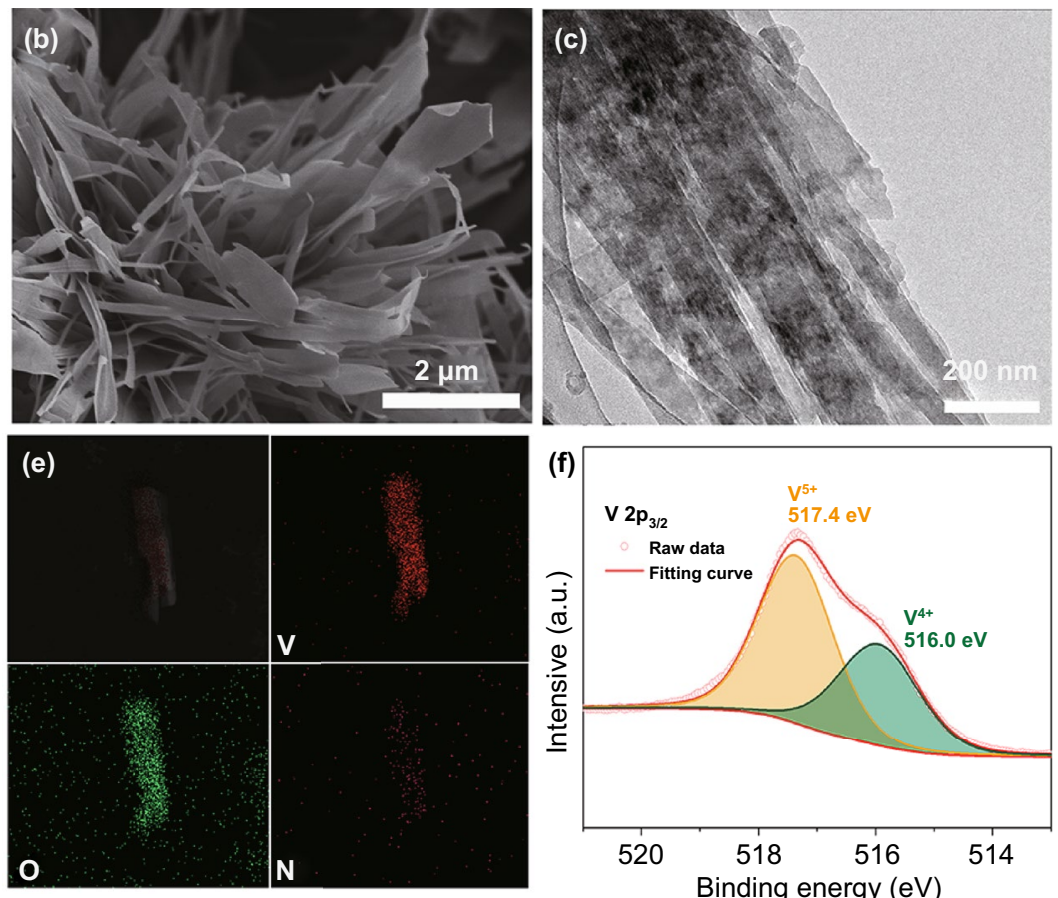

Fig. 2 Structural and morphological characterization of the NVO nanosheets. a, b SEM images, the ultrathin NVO sheets are grown on the carbon cloth uniformly. c TEM and d HRTEM images, a lattice spacing of $0.194 \mathrm{~nm}$ corresponds to the spacing of (403) plane. e Elemental mappings of $\mathrm{N}, \mathrm{O}$, and $\mathrm{V}$. Few $\mathrm{N}$ elements are detected due to the loss of ammonium ions. $\mathbf{X}$ XPS spectrum of V $2 \mathrm{p}_{3 / 2}$ 

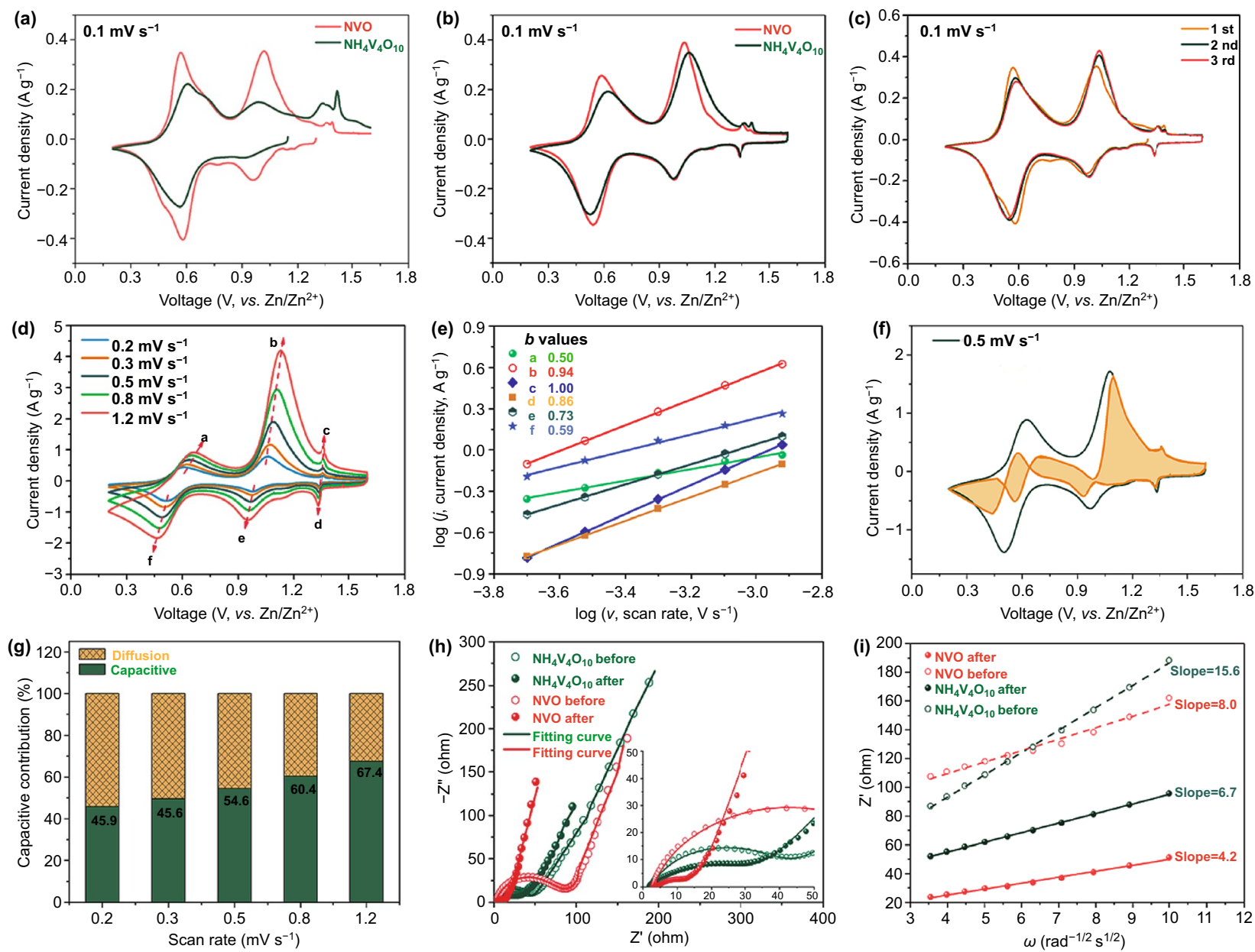

Fig. 3 Electrochemical reaction kinetics. Comparison of $\mathbf{a} 1^{\text {st }}$ cycle and $\mathbf{b} 3^{\text {rd }}$ cycle $\mathrm{CV}$ curves of $\mathrm{NH}_{4} \mathrm{~V}_{4} \mathrm{O}_{10}$ and $\mathrm{NVO}$ at a scan rate of $0.1 \mathrm{mV} \mathrm{s}^{-1}$. $\mathbf{c ~ C V}$ curves of $\mathrm{NVO}$ electrode in the first three cycles, the overlapped curves mean a highly reversible reaction. $\mathbf{d} \mathrm{CV}$ curves of $\mathrm{NVO}$ at different scan rates. $\mathrm{e}$ The relationship between peak currents and scan rates. $\mathbf{f}$ Capacitive contribution at $0.5 \mathrm{mV} \mathrm{s}{ }^{-1}$ in $\mathrm{NVO}(54.6 \%)$. $\mathrm{g}$

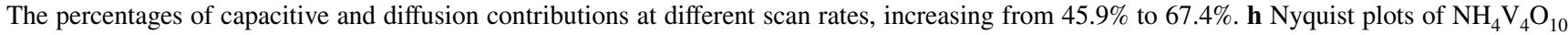
and NVO before and after CV test. i Relationship between the real part of impedance and low frequencies, smaller slopes of the lines mean fast zinc ion diffusion

spacing between layers or intralayer spacing in the layers [63]. The first discharge peak of NVO is stronger than that of $\mathrm{NH}_{4} \mathrm{~V}_{4} \mathrm{O}_{10}$, which is possibly due to the high content of $\mathrm{V}^{5+}$ and few ammonium ions. Compared to $\mathrm{NH}_{4} \mathrm{~V}_{4} \mathrm{O}_{10}$, more $\mathrm{V}^{5+}$ ions are reduced to $\mathrm{V}^{4+}$ and the zinc ions are easier to insert into interlayer at high voltage in $\mathrm{NVO}$, providing more capacity. The strong oxide peak of $\mathrm{NH}_{4} \mathrm{~V}_{4} \mathrm{O}_{10}$ at high voltage is attribute to the result of deammoniation. Comparing the third cycle at $0.1 \mathrm{mV} \mathrm{s}^{-1}$ in Fig. $3 \mathrm{~b}$, both $\mathrm{NVO}$ and $\mathrm{NH}_{4} \mathrm{~V}_{4} \mathrm{O}_{10}$ have two main pairs of redox peaks at around 1.0 and $0.5 \mathrm{~V}$, corresponding to the $\mathrm{V}^{5+} / \mathrm{V}^{4+}$ and $\mathrm{V}^{4+} / \mathrm{V}^{3+}$ redox pairs, respectively, and a pair of small peaks at about $1.3 \mathrm{~V}$ is also observed, which could be assigned to the occupancy in the intralayer spacing of $\mathrm{VO}$ polyhedra [61]. The first cycle of $\mathrm{CV}$ curves between $\mathrm{NVO}$ and $\mathrm{NH}_{4} \mathrm{~V}_{4} \mathrm{O}_{10}$ is quite different due to the irreversible deammoniation in $\mathrm{NH}_{4} \mathrm{~V}_{4} \mathrm{O}_{10}$, while the similar $\mathrm{CV}$ curves in third cycle are associated with the reduced deammoniation. The voltage gaps of redox peaks are summarized in Table 1. The NVO electrode shows smaller voltage gaps of both $\mathrm{V}^{5+} / \mathrm{V}^{4+}$ and $\mathrm{V}^{4+} / \mathrm{V}^{3+}$ redox pairs than those of $\mathrm{NH}_{4} \mathrm{~V}_{4} \mathrm{O}_{10}$ in the first and third cycle of $\mathrm{CV}$, respectively, suggesting the rapid ion diffusion and fast redox reaction kinetics. Both $\mathrm{NH}_{4} \mathrm{~V}_{4} \mathrm{O}_{10}$ and $\mathrm{NVO}$ in third cycle display increased voltage gaps for $\mathrm{V}^{4+} / \mathrm{V}^{3+}$ compared 
Table 1 Comparison of the peak positions and voltage gaps of three samples in the first and third cycle of CV

\begin{tabular}{llllll}
\hline Sample & & $\begin{array}{l}\text { Peak position in the first } \\
\text { cycle(V) }\end{array}$ & Voltage gap $(\mathrm{V})$ & \multicolumn{2}{l}{$\begin{array}{l}\text { Peak position in the third } \\
\text { cycle }(\mathrm{V})\end{array}$} \\
\hline $\mathrm{NVO}$ & $\mathrm{V}^{5+} / \mathrm{V}^{4+}$ & $1.01 / 0.96$ & 0.05 & $1.03 / 0.98$ & 0.05 \\
& $\mathrm{~V}^{4+} / \mathrm{V}^{3+}$ & $0.57 / 0.58$ & 0.01 & $0.59 / 0.54$ & 0.05 \\
$\mathrm{NH}_{4} \mathrm{~V}_{4} \mathrm{O}_{10}$ & $\mathrm{~V}^{5+} / \mathrm{V}^{4+}$ & $0.99 / 0.90$ & 0.09 & $1.06 / 0.98$ & 0.08 \\
& $\mathrm{~V}^{4+} / \mathrm{V}^{3+}$ & $0.61 / 0.56$ & 0.05 & $0.62 / 0.53$ & 0.09 \\
\hline
\end{tabular}

to the first cycle which are possibly ascribed to the incomplete deintercalation of zinc ions [64]. Figure 3c shows the CV curves of NVO electrode in the first three cycles. The overlapped CV curves mean a highly reversible reaction of the NVO cathode without the irreversible deammoniation in the ZIBs. It's worth noting that the discharge peak around $0.6 \mathrm{~V}$ shifts to a lower voltage in the subsequent cycles while other peaks move to higher voltage. Such changes also appear in $\mathrm{NH}_{4} \mathrm{~V}_{4} \mathrm{O}_{10}$, which are attributed to the distorted VO polyhedra resulting from the residual $\mathrm{Zn}^{2+}$ in the layers as discussed before. The differently curved shapes of the first two cycles in $\mathrm{NH}_{4} \mathrm{~V}_{4} \mathrm{O}_{10}$ imply an irreversible reaction (Fig. S5) because many $\mathrm{NH}_{4}^{+}$groups between the layers are expelled from the open spaces during the intercalation of zinc ions. The $\mathrm{CV}$ curves of $\mathrm{V}_{2} \mathrm{O}_{5}$ is quite different from $\mathrm{NVO}$ and $\mathrm{NH}_{4} \mathrm{~V}_{4} \mathrm{O}_{10}$ due to the different layered structure for the $\mathrm{Zn}^{2+}$ insertion/extraction (Fig. S7a).

The $\mathrm{CV}$ curves at different scan rates from 0.2 to $1.2 \mathrm{mV} \mathrm{s}^{-1}$ were measured to analyze the electrochemical reaction kinetics. All CV curves show similar shapes with the increase of scan rate as shown in Fig. 3d. The cathodic peaks shift toward higher potential and the anodic peaks move to lower voltages because of the polarization effect. The relationship of peak currents $(i)$ and sweep rate $(v)$ was investigated by using the following equation $[65,66]$ :

$i=a v^{b}$

where $a$ and $b$ are adjustable parameters. The value of $b$ can be determined by the slope of the straight line of $\log i$ vs $\log v$. A $b$-value of 1 indicates that the charge storage is surface-capacitive dominated, while the $b$-value of 0.5 represents a mass diffusion-controlled process. The $b$-values of peaks a-f in NVO were calculated to be $0.50,0.94,1.0,0.86$, $0.73,0.59$, respectively (Fig. 3e), whereas the corresponding values in $\mathrm{NH}_{4} \mathrm{~V}_{4} \mathrm{O}_{10}$ were $0.50,0.9,1.0,0.76,0.65,0.50$ (Fig. S6). The $b$-values suggest that the kinetics of the NVO and $\mathrm{NH}_{4} \mathrm{~V}_{4} \mathrm{O}_{10}$ are controlled by a combination of diffusion and capacitive behaviors, and the higher $b$-values in NVO indicate faster ion diffusion.

In addition, the contributions of capacitive $\left(k_{1} v\right)$ and diffusion-controlled $\left(k_{2} v^{1 / 2}\right)$ processes could be quantitatively calculated by the current density $(i)$ at a particular potential (V) and scan rate $(v)$, based on the following equation $[67,68]$ :

$i(V)=k_{1} v+k_{2} v^{1 / 2}$

The fitted CV curve at a scan rate of $0.5 \mathrm{mV} \mathrm{s}^{-1}$ is shown in Fig. 3f, in which the shadow area represents the capacitive contribution with a high value of $54.6 \%$. With increasing scan rates from 0.2 to $1.2 \mathrm{mV} \mathrm{s}^{-1}$, the contribution ratio of capacitive increases from $45.9 \%$ to $67.4 \%$ (Fig. 3g), indicating that the electrochemical behavior of the NVO nanosheets is mainly dominated by the capacitive process.

Nyquist plots consist of a semi-circle in the high-frequency section and a straight line in the low-frequency region. The diameter of the semicircle represents the charge transfer resistance $\left(R_{\mathrm{ct}}\right)$ and the slope of the line represents Warburg resistance $\left(\mathrm{Z}_{\mathrm{W}}\right)$ associating with ion diffusion. In Fig. $3 \mathrm{~h}$, the $R_{\mathrm{ct}}$ of $\mathrm{NVO}$ electrode before $\mathrm{CV}$ test is about 81 $\Omega$, which is higher than the $42 \Omega$ of $\mathrm{NH}_{4} \mathrm{~V}_{4} \mathrm{O}_{10}$. However, after 15 cycles of $\mathrm{CV}$ test, electrodes are activated, leading to reduced $R_{\mathrm{ct}}$ of two samples, the $R_{\mathrm{ct}}$ of NVO is decreased to $11 \Omega$, which is lower than the $30 \Omega$ of $\mathrm{NH}_{4} \mathrm{~V}_{4} \mathrm{O}_{10}$, due to fewer ammonium ions and larger interlayer spacing than $\mathrm{NH}_{4} \mathrm{~V}_{4} \mathrm{O}_{10}$. The relationship between low frequencies and the real part of impedance can be used to calculate the $\mathrm{Zn}$ ion diffusion coefficients $\left(D_{Z n^{2+}}\right)$ (details shown in ESI) $[69,70]$. The NVO electrode exhibits a higher $D_{Z n^{2+}}$ of $2.4 \times 10^{-13} \mathrm{~cm}^{2} \mathrm{~s}^{-1}$ than $\mathrm{NH}_{4} \mathrm{~V}_{4} \mathrm{O}_{10}$ of $6.3 \times 10^{-14} \mathrm{~cm}^{2} \mathrm{~s}^{-1}$, and retains the superiority after 15 cycles of $\mathrm{CV}$ test, with $8.7 \times 10^{-13} \mathrm{~cm}^{2} \mathrm{~s}^{-1}$ higher than $\mathrm{NH}_{4} \mathrm{~V}_{4} \mathrm{O}_{10}$ of $3.4 \times 10^{-13}$ $\mathrm{cm}^{2} \mathrm{~s}^{-1}$. These results show that the NVO electrode presents small charge transfer resistance and high $\mathrm{Zn}$-ion diffusion coefficient due to the weak interaction force between zinc 
ions and ammonium ions and large interlayer spacing, which are favorable for fast redox reaction.

\subsection{Electrochemical Properties of NVO}

The GCD profiles of $\mathrm{NVO}$ and $\mathrm{NH}_{4} \mathrm{~V}_{4} \mathrm{O}_{10}$ at a current density of $100 \mathrm{~mA} \mathrm{~g}^{-1}$ are compared in Fig. 4a. The plateaus during the charge/discharge process are consistent with the $\mathrm{CV}$ results. Obviously, the process of $\mathrm{Zn}^{2+}$ intercalation can be divided into two steps in $\mathrm{NVO}$ and $\mathrm{NH}_{4} \mathrm{~V}_{4} \mathrm{O}_{10}$. In the first step, the reduction of $\mathrm{V}^{5+}$ to $\mathrm{V}^{4+}$ in $\mathrm{NVO}$ delivers a capacity of $\sim 175 \mathrm{mAh} \mathrm{g}^{-1}$, which is higher than that of $\mathrm{NH}_{4} \mathrm{~V}_{4} \mathrm{O}_{10}$ $\left(\sim 120 \mathrm{mAh} \mathrm{g}^{-1}\right)$ due to the higher percentage of $\mathrm{V}^{5+}$ and large interlayer spacing for ions insertion. In the second step, the $\mathrm{V}^{4+}$ deriving from the first step and intrinsic $\mathrm{V}^{4+}$ ions are reduced to $\mathrm{V}^{3+}$, delivering a capacity of $\sim 280 \mathrm{mAh} \mathrm{g}^{-1}$. In addition, a lower charge plateau and a higher discharge plateau are observed in $\mathrm{NVO}$ electrode compared to $\mathrm{NH}_{4} \mathrm{~V}_{4} \mathrm{O}_{10}$ electrode, indicating that the $\mathrm{NVO}$ electrode possess higher energy efficiency than $\mathrm{NH}_{4} \mathrm{~V}_{4} \mathrm{O}_{10}$ electrode. The first three voltage profiles of NVO are shown in Fig. $4 \mathrm{~b}$, and the delivered specific capacity is $457 \mathrm{mAh} \mathrm{g}^{-1}$ at $100 \mathrm{~mA} \mathrm{~g}^{-1}$, which is high than that of other ammonium vanadate cathodes at the same current density, such as $\left(\mathrm{NH}_{4}\right)_{0.5} \mathrm{~V}_{2} \mathrm{O}_{5}\left(418.4 \mathrm{mAh} \mathrm{g}^{-1}\right)$ [49], $\left(\mathrm{NH}_{4}\right)_{2} \mathrm{~V}_{4} \mathrm{O}_{9}\left(378 \mathrm{mAh} \mathrm{g}^{-1}\right)$ [51], $\left(\mathrm{NH}_{4}\right)_{2} \mathrm{~V}_{6} \mathrm{O}_{16} \cdot 1.5 \mathrm{H}_{2} \mathrm{O}$ (385 $\mathrm{mAh} \mathrm{g}^{-1}$ ) [32], and $\mathrm{NH}_{4} \mathrm{~V}_{3} \mathrm{O}_{8} \cdot 0.5 \mathrm{H}_{2} \mathrm{O}\left(423 \mathrm{mAh} \mathrm{g}^{-1}\right)$ [71]. The initial coulombic efficiency of NVO could reach up to $97 \%$, much higher than that of $\mathrm{NH}_{4} \mathrm{~V}_{4} \mathrm{O}_{10}(85 \%$, Fig. $\mathrm{S} 7$ ), because a small number of $\mathrm{NH}_{4}^{+}$ions in the interlayers do not act as barriers for the first intercalation of zinc ions. In the subsequent two cycles, the specific capacities are slightly increased due to the activated process and the GCD curves overlap well, suggesting a good reversibility of the $\mathrm{NVO}$ electrode during electrochemical reactions. However, the voltage profiles of $\mathrm{NH}_{4} \mathrm{~V}_{4} \mathrm{O}_{10}$ electrode exhibit different sharps in the first three cycles due to the irreversible deammoniation (Fig. S7). Figure $4 \mathrm{c}$ shows the rate performance of $\mathrm{NVO}$ and $\mathrm{NH}_{4} \mathrm{~V}_{4} \mathrm{O}_{10}$. The $\mathrm{NVO}$ electrode delivers an initial specific capacity of $397 \mathrm{mAh} \mathrm{g}^{-1}$ at a current density of $0.5 \mathrm{~A} \mathrm{~g}^{-1}$, and the capacity of $\mathrm{NH}_{4} \mathrm{~V}_{4} \mathrm{O}_{10}$ electrode is $270 \mathrm{mAh} \mathrm{g}^{-1}$. For the second cycle, the capacity of NVO could reach to $403 \mathrm{mAh} \mathrm{g}^{-1}$, which is higher than that of $\mathrm{NH}_{4} \mathrm{~V}_{4} \mathrm{O}_{10}\left(336 \mathrm{mAh} \mathrm{g}^{-1}\right)$. The specific capacities of $\mathrm{NVO}$ at different current densities of $1,2,4$, and $5 \mathrm{~A} \mathrm{~g}^{-1}$ are 357 , 294, 203, and $170 \mathrm{mAh} \mathrm{g}^{-1}$, respectively, while $\mathrm{NH}_{4} \mathrm{~V}_{4} \mathrm{O}_{10}$ delivers lower capacities of $288,214,114$, and $95 \mathrm{mAh} \mathrm{g}^{-1}$
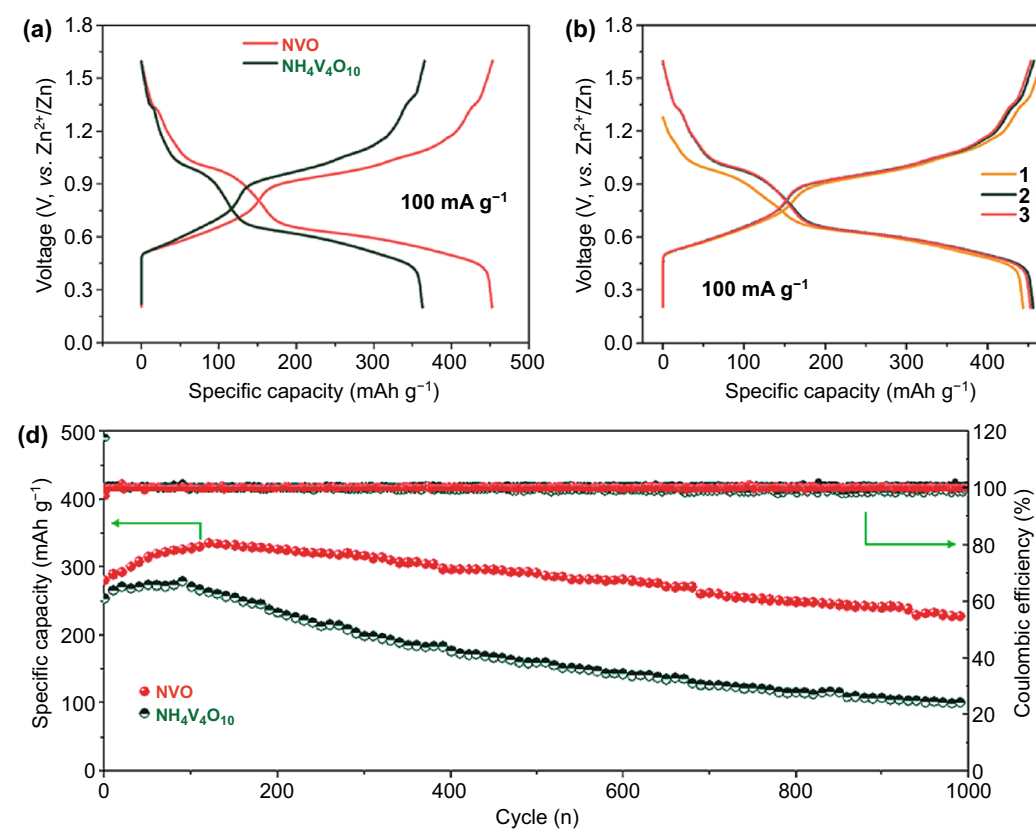
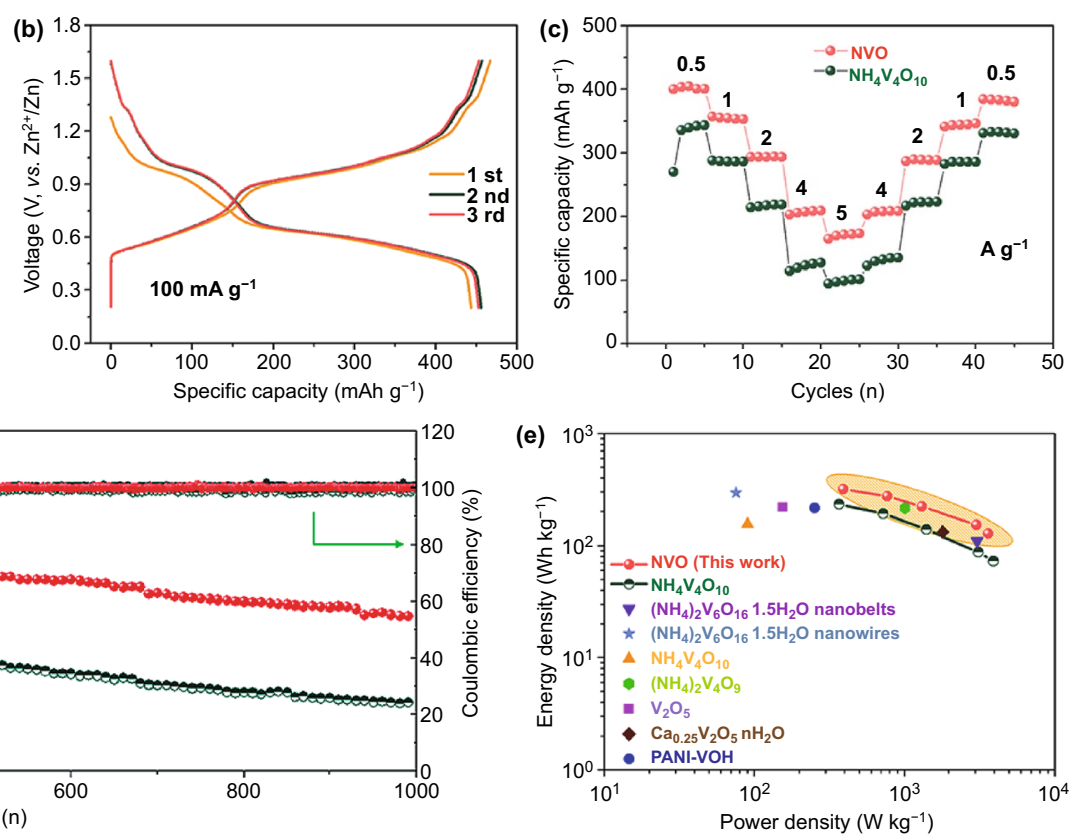

Fig. 4 Electrochemical performance of NVO and $\mathrm{NH}_{4} \mathrm{~V}_{4} \mathrm{O}_{10}$. a Comparison of GCD plots at $100 \mathrm{~mA} \mathrm{~g}^{-1}$. $\mathbf{b}$ GCD curves of NVO in first three cycles. c Rate performance of $\mathrm{NVO}$ and $\mathrm{NH}_{4} \mathrm{~V}_{4} \mathrm{O}_{10}$. d Cycling stability with the corresponding coulombic efficiencies at $2 \mathrm{~A}^{-1}$. e Ragone plots in comparison with other cathodes, such as $\left(\mathrm{NH}_{4}\right)_{2} \mathrm{~V}_{6} \mathrm{O}_{16} \cdot 1.5 \mathrm{H}_{2} \mathrm{O}$ nanobelts [48], $\left(\mathrm{NH}_{4}\right)_{2} \mathrm{~V}_{6} \mathrm{O}_{16} \cdot 1.5 \mathrm{H}_{2} \mathrm{O}$ nanowires [32], $\mathrm{NH}_{4} \mathrm{~V}_{4} \mathrm{O}_{10}$ [50], $\left(\mathrm{NH}_{4}\right)_{2} \mathrm{~V}_{4} \mathrm{O}_{9}$ [51], $\mathrm{V}_{2} \mathrm{O}_{5}$ [73], $\mathrm{Ca}_{0.25} \mathrm{~V}_{2} \mathrm{O}_{5} \cdot \mathrm{nH}_{2} \mathrm{O}$ [74], PANI-VOH [75] 
at the corresponding current densities. When the current densities decrease back to $0.5 \mathrm{~A} \mathrm{~g}^{-1}$, the capacities recover to the initial values, suggesting a stable crystal structure and great electrochemical reversibility. Compared to $\mathrm{NH}_{4} \mathrm{~V}_{4} \mathrm{O}_{10}$ and $\mathrm{V}_{2} \mathrm{O}_{5}$, the improved capacity and rate performance of NVO could be attributed to the large interlayer spacing and abundant active sites for fast zinc ion diffusion and facile accommodation (Fig. S7). The ordinary rate performance of free-standing NVO could be attributed to no additional conductive agent, which restricts the charge transfer. The galvanostatic charge-discharge profiles of NVO at different current densities are shown in Fig. S8. Cycling stability and corresponding Coulombic efficiencies of NVO and $\mathrm{NH}_{4} \mathrm{~V}_{4} \mathrm{O}_{10}$ electrodes were evaluated at a current density of $2 \mathrm{~A} \mathrm{~g}^{-1}$ in Fig. $4 \mathrm{~d}$. The $\mathrm{NH}_{4} \mathrm{~V}_{4} \mathrm{O}_{10}$ electrode remained only $\sim 40 \%$ retention of the initial capacity after 1000 cycles and exhibited fluctuant Coulombic efficiencies during cycling test. The fast capacity fading could be attributed to structure degradation caused by the irreversible deammoniation during the long-term cycle. For NVO electrode, the first discharge capacity was $280 \mathrm{mAh} \mathrm{g}^{-1}$ and reached up to $335 \mathrm{mAh} \mathrm{g}^{-1}$ after the initial 120 cycles, due to the electrochemical activation, still maintaining a capacity of 227 $\mathrm{mAh} \mathrm{g}^{-1}$ after 1000 cycles. The activated process is possibly attributed to the incomplete deintercalation of zinc ions, which act as "pillars" in the interlayer to improve the structural stability and contribute to the enhanced capacity. The microstructure of NVO nanosheets is maintained well after cycling test as shown in Fig. S9. The decay of the specific capacity could be attributed to the aggregation of by-product on the surface of NVO nanosheets during the repeated charge/discharge test. The by-product could be confirmed as $\mathrm{Zn}_{3} \mathrm{~V}_{2} \mathrm{O}_{7}(\mathrm{OH})_{2} \cdot 2 \mathrm{H}_{2} \mathrm{O}$ (JCPDS No. 87-0417) from the $\mathrm{XRD}$ of sample after cycling, which has a side effect on the cycling performance of NVO (Fig. S11) [72]. Besides, the NVO showed high Coulombic efficiencies of near to $100 \%$ in the 1000 cycles, indicating the high reversibility. The improved cycling stability could be attributed to the little change of the structure without the side effect of deammoniation and the residual ammonium ions after heat treatment stabilizing the structure. The comparison of electrochemical performance of previous reported ammonium vanadates and our NVO nanosheets is given in Table S1. The Ragone plots (Fig. 4e) comparing $\mathrm{NVO}$ and $\mathrm{NH}_{4} \mathrm{~V}_{4} \mathrm{O}_{10}$ nanosheets with some typical cathodes such as $\left(\mathrm{NH}_{4}\right)_{2} \mathrm{~V}_{6} \mathrm{O}_{16} \cdot 1.5 \mathrm{H}_{2} \mathrm{O}$ nanobelts [48], $\left(\mathrm{NH}_{4}\right)_{2} \mathrm{~V}_{6} \mathrm{O}_{16} \cdot 1.5 \mathrm{H}_{2} \mathrm{O}$ nanowires [32], $\mathrm{NH}_{4} \mathrm{~V}_{4} \mathrm{O}_{10}$
[50], $\left(\mathrm{NH}_{4}\right)_{2} \mathrm{~V}_{4} \mathrm{O}_{9}$ [51], $\mathrm{V}_{2} \mathrm{O}_{5}$ [73], $\mathrm{Ca}_{0.25} \mathrm{~V}_{2} \mathrm{O}_{5} \cdot \mathrm{nH}_{2} \mathrm{O}$ [74], PANI-VOH [75]. A remarkable energy density of $317 \mathrm{Wh}$ $\mathrm{kg}^{-1}$ was delivered at a power density of $392 \mathrm{~W} \mathrm{~kg}^{-1}$ based on the mass of active materials, which was higher than that of $\mathrm{NH}_{4} \mathrm{~V}_{4} \mathrm{O}_{10}\left(232.5 \mathrm{Wh} \mathrm{kg}^{-1}\right.$ at $\left.367 \mathrm{~W} \mathrm{~kg}^{-1}\right)$.

\subsection{Charge Storage Mechanism of NVO}

Some ex-situ characterizations were employed to study the charge storage mechanism of NVO electrode in Fig. 5. The phases changes of NVO nanosheets during the first charging-discharging process were analyzed using ex situ XRD characteristics in Fig. 5a. Compared to pristine NVO, new peaks located at $12.3^{\circ}, 32.1^{\circ}, 60.6^{\circ}$, and $62.6^{\circ}$ are indexed to $\mathrm{Zn}_{3} \mathrm{~V}_{2} \mathrm{O}_{7}(\mathrm{OH})_{2} \cdot 2 \mathrm{H}_{2} \mathrm{O}$ (JCPDS No. 87-0417), which has been reported in previous studies [47, 52, 76]. Generally, $\mathrm{Zn}^{2+}$ could be coordinated with water molecules in the aqueous electrolyte to form large $\left[\mathrm{Zn}\left(\mathrm{H}_{2} \mathrm{O}\right)_{6}\right]^{2+}$ [77]. Because of the weakened $\mathrm{O}-\mathrm{H}$ bond affected by $\mathrm{Zn}^{2+}$ in $\mathrm{H}_{2} \mathrm{O}$, the $\mathrm{OH}^{-}$might originate from the broken $\mathrm{O}-\mathrm{H}$ bond and react with $\mathrm{VO}$ in the layers to form $\mathrm{Zn}_{3} \mathrm{~V}_{2} \mathrm{O}_{7}(\mathrm{OH})_{2} \cdot 2 \mathrm{H}_{2} \mathrm{O}$. At the same time, we suspect that the generating $\mathrm{H}^{+}$would not exist in the electrolyte but possibly insert into the cathode materials [78]. In addition, during the first discharge, the (001) peak of NVO shifted slightly to high angle area, indicating shrinkage of the interlayer spacing upon $\mathrm{Zn}$-intercalation. When discharged to $0.2 \mathrm{~V}$, the (001) peak moves to the high angle of $9.06^{\circ}$ with the interlayer distance decreased to $9.8 \AA$, which is possibly attributed to the strong electrostatic interaction between $\mathrm{Zn}^{2+}$ and negative single-connected oxygen. Upon the first charge, the (001) peak of NVO returns and the peaks of $\mathrm{Zn}_{3} \mathrm{~V}_{2} \mathrm{O}_{7}(\mathrm{OH})_{2} \cdot 2 \mathrm{H}_{2} \mathrm{O}$ disappear, demonstrating the reversibility of the phase transition.

Ex situ SEM was conducted to study the changes of morphologies during the first charge/discharge process in Fig. 5b-e. When discharged to $0.6 \mathrm{~V}$, some nanoparticles appear on the surface of the NVO nanosheets (Fig. 5b), which could be the growth of $\mathrm{Zn}_{3} \mathrm{~V}_{2} \mathrm{O}_{7}(\mathrm{OH})_{2} \cdot 2 \mathrm{H}_{2} \mathrm{O}$. After fully discharged, the surface of the electrode is fully covered by this by-product (Fig. 5c). When charged to $0.8 \mathrm{~V}$, the $\mathrm{Zn}_{3} \mathrm{~V}_{2} \mathrm{O}_{7}(\mathrm{OH})_{2} \cdot 2 \mathrm{H}_{2} \mathrm{O}$ layer begins to be decomposed and form the nanoparticles (Fig. 5d). As shown in Fig. 5e, after the electrode is charged to $1.6 \mathrm{~V}$, the $\mathrm{Zn}_{3} \mathrm{~V}_{2} \mathrm{O}_{7}(\mathrm{OH})_{2} \cdot 2 \mathrm{H}_{2} \mathrm{O}$ by-product is decomposed completely and the surface becomes smooth. The results of ex situ SEM suggest that 

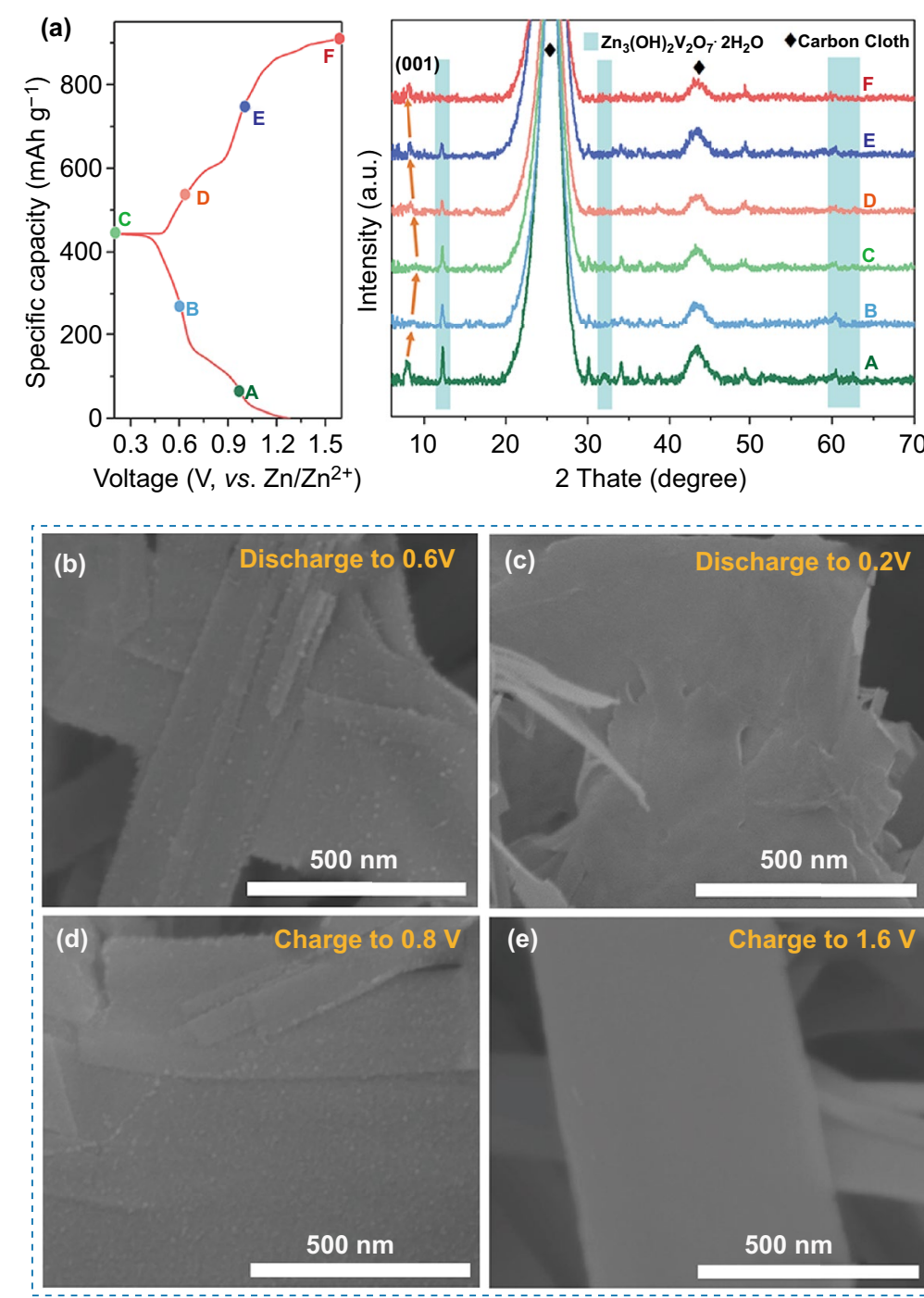
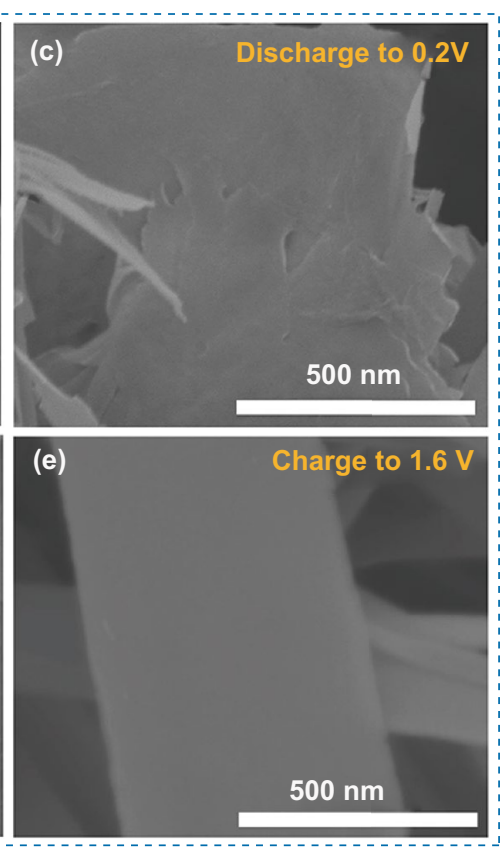
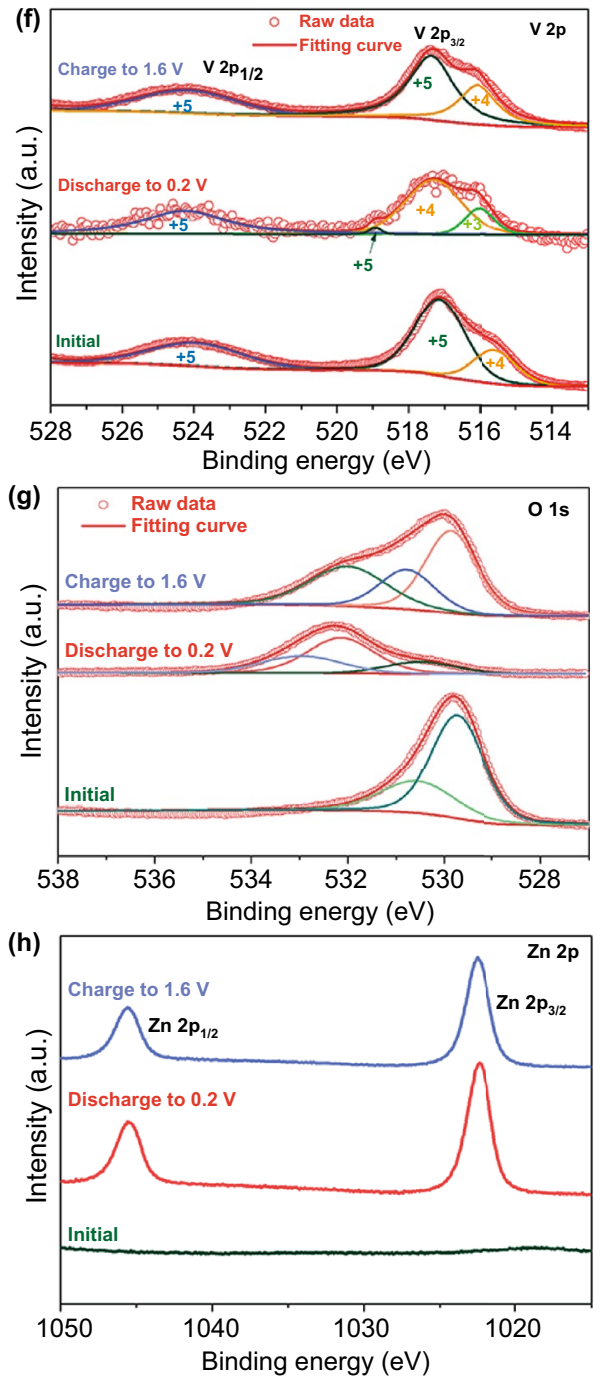

Fig. 5 Electrochemical reaction process studies. a Ex situ XRD patterns of NVO in different discharge/charge states, the shifts and recovery of (001) peaks suggest a reversible reaction in the electrochemical processes. Ex situ SEM of NVO in the first discharge/charge process, $\mathbf{b}$ discharge to $0.6 \mathrm{~V}$, $\mathbf{c}$ discharge to $0.2 \mathrm{~V}$, $\mathbf{d}$ charge to $0.8 \mathrm{~V}$, e charge to $1.6 \mathrm{~V}$. Ex situ XPS spectra of $\mathbf{f} \mathrm{V} 2 \mathrm{p}, \mathbf{g}$ O $1 \mathrm{~s}, \mathbf{h} \mathrm{Zn} 2 \mathrm{p}$ in the initial, discharge to $0.2 \mathrm{~V}$ and charge to $1.6 \mathrm{~V}$ states in the first cycle

the formation and decomposition of $\mathrm{Zn}_{3} \mathrm{~V}_{2} \mathrm{O}_{7}(\mathrm{OH})_{2} \cdot 2 \mathrm{H}_{2} \mathrm{O}$ are highly reversible. This process was further confirmed by the ex situ TEM in Fig. S12. A lattice spacing of $0.246 \mathrm{~nm}$ can be observed at the fully discharged state, corresponding to the (201) plane of the new phase of $\mathrm{Zn}_{3} \mathrm{~V}_{2} \mathrm{O}_{7}(\mathrm{OH})_{2} \cdot 2 \mathrm{H}_{2} \mathrm{O}$ (Fig. S12a). After charging to $1.6 \mathrm{~V}$, the electrode exhibits the characteristic of NVO, suggesting the good reversibility (Fig. S12b). EDS mapping in Fig. S12c, d shows the distribution of N, V, O, and Zn elements at the fully discharged and charged states. The $\mathrm{Zn}$ signal at the fully charged could originate from the absorbed $\mathrm{Zn}^{2+}$ or $\mathrm{Zn}^{2+}$ existing in the crystal lattice.
The V 2p XPS spectra of NVO at different electrochemical stages are shown in Fig. 5f. When discharged to $0.2 \mathrm{~V}$, the $\mathrm{V}^{5+}$ cations are reduced to $\mathrm{V}^{4+}$ and $\mathrm{V}^{3+}$ due to the insertion of zinc ions. The existence of $\mathrm{V}^{5+}$ state could be attributed to the $\mathrm{Zn}_{3} \mathrm{~V}_{2} \mathrm{O}_{7}(\mathrm{OH})_{2} \cdot 2 \mathrm{H}_{2} \mathrm{O}$ by-product and the incomplete redox reaction results that the delivered specific capacity is lower than theoretical capacity. In addition, the peaks shift towards higher binding energy in the fully discharged state because the inserted zinc ions could affect the distribution of electron [79]. After charged to $1.6 \mathrm{~V}$, the $\mathrm{V}$ cations are oxidized, and the $\mathrm{V} 2 \mathrm{p}$ spectrum is similar to that of initial state, suggesting good reversible redox reactions. 
Figure $5 \mathrm{~g}$ shows the XPS spectra of O $1 \mathrm{~s}$. After the first discharging process, the peaks located at around 532.5 and $533.0 \mathrm{eV}$ are attributed to water molecules and $\mathrm{OH}^{-}$, respectively, indicating to the insertion of hydrated zinc ions and the formation of $\mathrm{Zn}_{3} \mathrm{~V}_{2} \mathrm{O}_{7}(\mathrm{OH})_{2} \cdot 2 \mathrm{H}_{2} \mathrm{O}$ [80]. After charging to $1.6 \mathrm{~V}$, the $\mathrm{H}_{2} \mathrm{O}$ signal is retained while the $\mathrm{OH}^{-}$signal disappears, which further suggests the decomposition of $\mathrm{Zn}_{3} \mathrm{~V}_{2} \mathrm{O}_{7}(\mathrm{OH})_{2} \cdot 2 \mathrm{H}_{2} \mathrm{O}$. There is no peaks of $\mathrm{Zn} 2 \mathrm{p}$ in the pristine NVO (Fig. 5h), while two peaks corresponding to $\mathrm{Zn} 2 \mathrm{p}_{1 / 2}(1045.6 \mathrm{eV})$ and $\mathrm{Zn} 2 \mathrm{p}_{3 / 2}(1022.5 \mathrm{eV})$ appear in the fully discharged state, indicating the intercalation of zinc ions [81]. The $\mathrm{Zn} 2 \mathrm{p}$ signals in the fully charged state are also detected, which is consistent with the results of ex situ TEM.

GITT plots were measured at a current density of $50 \mathrm{~mA} \mathrm{~g}^{-1}$ to calculate the diffusion coefficients of the zinc ions as shown in Fig. 6a, b (details supplied in Supporting information) $[82,83]$. The $D_{\mathrm{Zn}}$ values of NVO during both the insertion and extraction processes are within the orders of $10^{-10}$ to $10^{-12} \mathrm{~cm}^{2} \mathrm{~s}^{-1}$, superior to those of $\mathrm{NH}_{4} \mathrm{~V}_{4} \mathrm{O}_{10}$, indicating the fast $\mathrm{Zn}$-ion diffusion ability, which is agreement with the EIS results. From ex situ characterizations and GITT plots, the zinc ions insertion/extraction process in NVO could be deduced. In the discharging process, the $D_{\mathrm{Zn}}$ value goes through four stages: stabilization, gradual decline, fluctuating rise, and sharp decline. The $D_{\mathrm{Zn}}$ values remain unchanged at the beginning of discharging process (Region I) due to large interlayer space for the insertion of hydrated zinc ions. When discharged to $0.9 \mathrm{~V}$ (Region II), the $D_{\mathrm{Zn}}$ values decrease gradually which is possibly attributed to the difficult insertion of large sized $\left[\mathrm{Zn}\left(\mathrm{H}_{2} \mathrm{O}\right)_{6}\right]^{2+}$. Then, the $D_{\mathrm{Zn}}$ value exhibits a tendency of fluctuating increasement (Region III) which is possibly attributed to the desolvation of $\left[\mathrm{Zn}\left(\mathrm{H}_{2} \mathrm{O}\right)_{6}\right]^{2+}$ and easier intercalation process of small $\mathrm{Zn}^{2+}$. After discharged to $0.5 \mathrm{~V}$ (Region IV), the $D_{\mathrm{Zn}}$ value decreases dramatically because no channels are available for ions intercalation. When charged to $0.8 \mathrm{~V}$ (Region I), the $D_{\mathrm{Zn}}$ value decreases gradually owing to the deintercalation
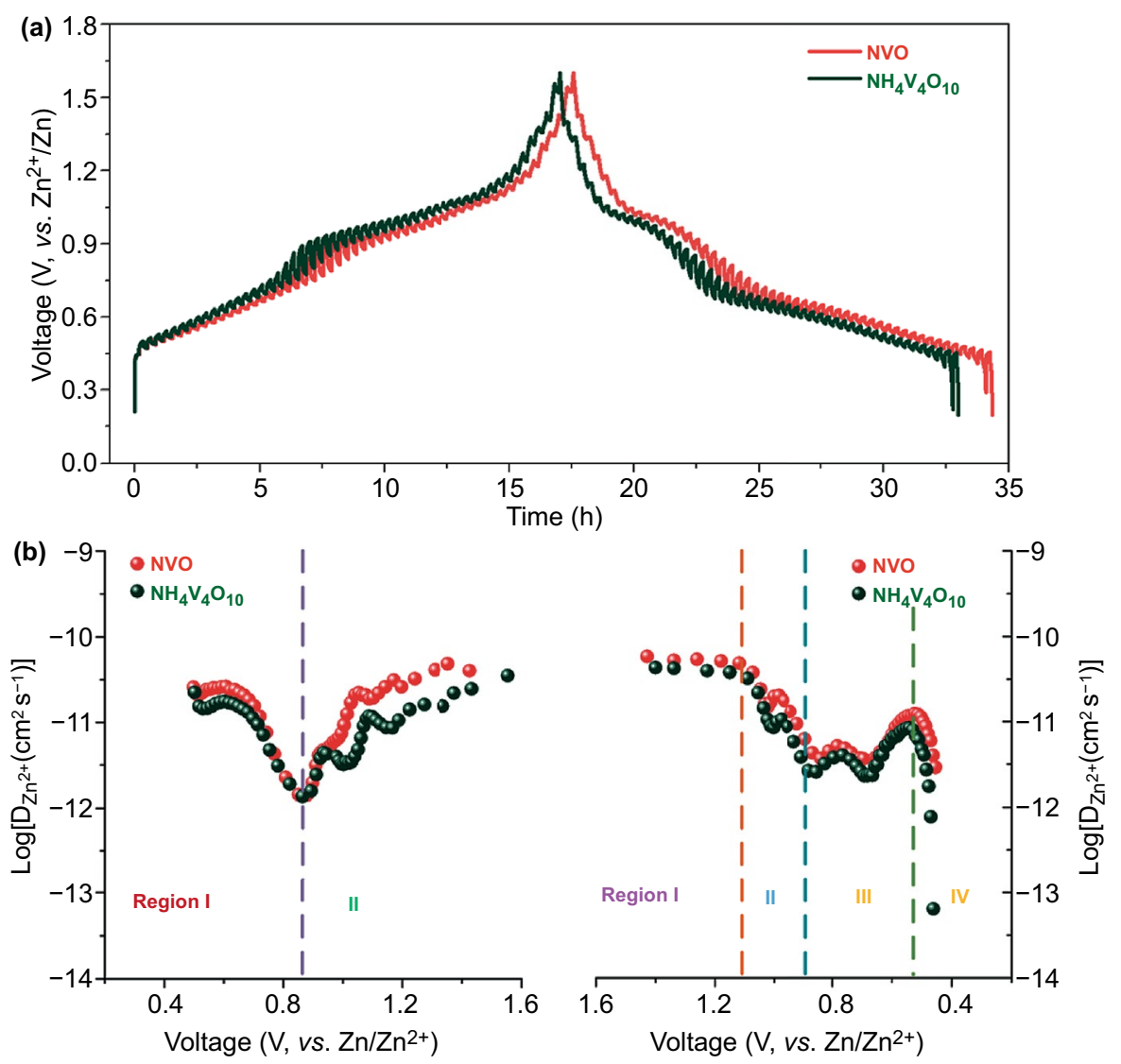

Fig. 6 Analysis of ions insertion/extraction process. a GITT tests at a current density of $50 \mathrm{~mA} \mathrm{~h} \mathrm{~g}{ }^{-1}$. b Corresponding ion diffusion coefficients of $\mathrm{NVO}$ and $\mathrm{NH}_{4} \mathrm{~V}_{4} \mathrm{O}_{10}$ 
of $\mathrm{Zn}^{2+}$. After $0.8 \mathrm{~V}$ (Region II), the increase in $D_{\mathrm{Zn}}$ value is attributed to decomposition of $\mathrm{Zn}_{3} \mathrm{~V}_{2} \mathrm{O}_{7}(\mathrm{OH})_{2} \cdot 2 \mathrm{H}_{2} \mathrm{O}$ and then producing more $\mathrm{Zn}^{2+}$.

\section{Conclusions}

Pre-removing some ammonium ions from $\mathrm{NH}_{4} \mathrm{~V}_{4} \mathrm{O}_{10}$ not only expanded the interlayer spacing but also produced many active sites, which offered more diffusion pathways, facilitated the zinc ions insertion/extraction and alleviate cycling decay caused by the irreversible dissolution of ammonium ions during cycles. The NVO electrode exhibits a high initial Coulombic efficiency of $97 \%$ compared to $85 \%$ of $\mathrm{NH}_{4} \mathrm{~V}_{4} \mathrm{O}_{10}$ electrode and delivers a high specific capacity of $457 \mathrm{mAh} \mathrm{g}^{-1}$ at a current density of $100 \mathrm{~mA} \mathrm{~g}^{-1}$ compared to $363 \mathrm{mAh} \mathrm{g}^{-1}$ of $\mathrm{NH}_{4} \mathrm{~V}_{4} \mathrm{O}_{10}$ electrode as well as a long-term cycling stability ( $81 \%$ of initial capacity after 1000 cycles) compared to $40 \%$ of $\mathrm{NH}_{4} \mathrm{~V}_{4} \mathrm{O}_{10}$ electrode. The $e x$-situ characterizations (XRD, SEM, TEM, and XPS) demonstrated reversible $\mathrm{Zn}_{3} \mathrm{~V}_{2} \mathrm{O}_{7}(\mathrm{OH})_{2} \cdot 2 \mathrm{H}_{2} \mathrm{O}$ formation/ decomposition in $\mathrm{NVO}$ during charge/discharge processes. This work provides a novel strategy of deionized method for designing high-performance cathode materials for ZIBs and other multivalent ion batteries.

Acknowledgements This work was supported by the National Science Foundation (CBET-1803256), National Natural Science Foundation of China (Grant No. 51772267), the National Key R\&D Program of China (Grant No. 2016YFB0401501), and the Key R\&D Program of Zhejiang Province (Grant No. 2020C01004). The author acknowledges the financial support from China Scholarship Council (No. 201906320198) and 2019 Zhejiang University Academic Award for Outstanding Doctoral Candidates. The authors are grateful to the Deanship of Scientific Research, King Saud University for funding through Vice Deanship of Scientific Research Chairs.

Open Access This article is licensed under a Creative Commons Attribution 4.0 International License, which permits use, sharing, adaptation, distribution and reproduction in any medium or format, as long as you give appropriate credit to the original author(s) and the source, provide a link to the Creative Commons licence, and indicate if changes were made. The images or other third party material in this article are included in the article's Creative Commons licence, unless indicated otherwise in a credit line to the material. If material is not included in the article's Creative Commons licence and your intended use is not permitted by statutory regulation or exceeds the permitted use, you will need to obtain permission directly from the copyright holder. To view a copy of this licence, visit http://creativecommons.org/licenses/by/4.0/.
Supplementary Information The online version contains supplementary material available at https://doi.org/10.1007/ s40820-021-00641-3.

\section{References}

1. S. Liu, L. Kang, J.M. Kim, Y.T. Chun, J. Zhang et al., Recent advances in vanadium-based aqueous rechargeable zinc-ion batteries. Adv. Energy Mater. 10(25), 2000477 (2020). https:// doi.org/10.1002/aenm.202000477

2. H. Li, L. Ma, C. Han, Z. Wang, Z. Liu et al., Advanced rechargeable zinc-based batteries: Recent progress and future perspectives. Nano Energy 62, 550-587 (2019). https://doi. org/10.1016/j.nanoen.2019.05.059

3. X. Jia, C. Liu, Z.G. Neale, J. Yang, G. Cao, Active materials for aqueous zinc ion batteries: Synthesis, crystal structure, morphology, and electrochemistry. Chem. Rev. 120(15), 7795-7866 (2020). https://doi.org/10.1021/acs.chemrev.9b006 28

4. R. Li, H. Zhang, Q. Zheng, X. Li, Porous $\mathrm{V}_{2} \mathrm{O}_{5}$ yolk-shell microspheres for zinc ion battery cathodes: Activation responsible for enhanced capacity and rate performance. J. Mater. Chem. A 8(10), 5186-5193 (2020). https://doi.org/10.1039/ c9ta11750d

5. C. Liu, R. Massé, X. Nan, G. Cao, A promising cathode for li-ion batteries: $\mathrm{Li}_{3} \mathrm{~V}_{2}\left(\mathrm{PO}_{4}\right)_{3}$. Energy Storage Mater. 4, 15-58 (2016). https://doi.org/10.1016/j.ensm.2016.02.002

6. J.B. Goodenough, K.S. Park, The Li-ion rechargeable battery: A perspective. J. Am. Chem. Soc. 135(4), 1167-1176 (2013). https://doi.org/10.1021/ja3091438

7. Z. Li, Y. Peng, C. Liu, X. Zhang, X. Li et al., Oxygen-deficient $\mathrm{TiO}_{2}$ yolk-shell spheres for enhanced lithium storage properties. Energy Environ. Mater. 4(1), 1-7 (2021). https://doi.org/ 10.1002/eem2.12156

8. A. Konarov, N. Voronina, J.H. Jo, Z. Bakenov, Y.-K. Sun et al., Present and future perspective on electrode materials for rechargeable zinc-ion batteries. ACS Energy Lett. 3(10), 2620-2640 (2018). https://doi.org/10.1021/acsenergylett. $8 \mathrm{~b} 01552$

9. L.E. Blanc, D. Kundu, L.F. Nazar, Scientific challenges for the implementation of Zn-ion batteries. Joule 4(4), 771-799 (2020). https://doi.org/10.1016/j.joule.2020.03.002

10. J. Lang, C. Jiang, Y. Fang, L. Shi, S. Miao et al., Room-temperature rechargeable $\mathrm{Ca}$-ion based hybrid batteries with high rate capability and long-term cycling life. Adv. Energy Mater. 9(29), 1901099 (2019). https://doi.org/10.1002/aenm.20190 1099

11. X. Deng, Y. Xu, Q. An, F. Xiong, S. Tan et al., Manganese ion pre-intercalated hydrated vanadium oxide as a high-performance cathode for magnesium ion batteries. J. Mater. Chem. A 7(17), 10644-10650 (2019). https://doi.org/10.1039/c8ta1 $1236 \mathrm{c}$

12. K. Yao, Z. Xu, J. Huang, M. Ma, L. Fu et al., Bundled defectrich $\mathrm{MoS}_{2}$ for a high-rate and long-life sodium-ion battery: 
Achieving 3D diffusion of sodium ion by vacancies to improve kinetics. Small 15(12), 1805405 (2019). https://doi.org/10. 1002/smll.201805405

13. J. Li, N. Zhuang, J. Xie, X. Li, W. Zhuo et al., K-ion storage enhancement in $\mathrm{Sb}_{2} \mathrm{O}_{3}$ /reduced graphene oxide using etherbased electrolyte. Adv. Energy Mater. 10(5), 1903455 (2019). https://doi.org/10.1002/aenm.201903455

14. M. Song, H. Tan, D. Chao, H.J. Fan, Recent advances in Znion batteries. Adv. Funct. Mater. 28(41), 1802564 (2018). https://doi.org/10.1002/adfm.201802564

15. W. Du, E.H. Ang, Y. Yang, Y. Zhang, M. Ye et al., Challenges in the material and structural design of zinc anode towards high-performance aqueous zinc-ion batteries. Energy Environ. Sci. 13(10), 3330-3360 (2020). https://doi.org/10.1039/d0ee0 $2079 f$

16. J. Hao, X. Li, X. Zeng, D. Li, J. Mao et al., Deeply understanding the $\mathrm{Zn}$ anode behaviour and corresponding improvement strategies in different aqueous Zn-based batteries. Energy Environ. Sci. 13(11), 3917-3949 (2020). https://doi.org/10. 1039/d0ee02162h

17. Q. Zhang, C. Li, Q. Li, Z. Pan, J. Sun et al., Flexible and highvoltage coaxial-fiber aqueous rechargeable zinc-ion battery. Nano Lett. 19(6), 4035-4042 (2019). https://doi.org/10.1021/ acs.nanolett.9b01403

18. J. Wang, J.-G. Wang, H. Liu, C. Wei, F. Kang, Zinc ion stabilized $\mathrm{MnO}_{2}$ nanospheres for high capacity and long lifespan aqueous zinc-ion batteries. J. Mater. Chem. A 7(22), 1372713735 (2019). https://doi.org/10.1039/c9ta03541a

19. Y. Jiang, D. Ba, Y. Li, J. Liu, Noninterference revealing of "layered to layered" zinc storage mechanism of $\delta-\mathrm{MnO}_{2}$ toward neutral $\mathrm{Zn}-\mathrm{Mn}$ batteries with superior performance. Adv. Sci. 7(6), 1902795 (2020). https://doi.org/10.1002/advs. 201902795

20. Q. Zhang, L. Li, H. Li, L. Tang, B. He et al., Ultra-endurance coaxial-fiber stretchable sensing systems fully powered by sunlight. Nano Energy 60, 267-274 (2019). https://doi.org/ 10.1016/j.nanoen.2019.03.049

21. C. Liu, Z. Neale, J. Zheng, X. Jia, J. Huang et al., Expanded hydrated vanadate for high-performance aqueous zinc-ion batteries. Energy Environ. Sci. 12(7), 2273-2285 (2019). https:// doi.org/10.1039/c9ee00956f

22. X. Wang, Y. Li, S. Wang, F. Zhou, P. Das et al., 2D amorphous $\mathrm{V}_{2} \mathrm{O}_{5}$ /graphene heterostructures for high-safety aqueous $\mathrm{Zn}$-ion batteries with unprecedented capacity and ultrahigh rate capability. Adv. Energy Mater. 10(22), 2000081 (2020). https://doi.org/10.1002/aenm.202000081

23. Y. Yang, Y. Tang, G. Fang, L. Shan, J. Guo et al., $\mathrm{Li}^{+}$intercalated $\mathrm{V}_{2} \mathrm{O}_{5} \cdot \mathrm{nH}_{2} \mathrm{O}$ with enlarged layer spacing and fast ion diffusion as an aqueous zinc-ion battery cathode. Energy Environ. Sci. 11(11), 3157-3162 (2018). https://doi.org/10.1039/ c8ee01651h

24. Z. Li, Y. Ren, L. Mo, C. Liu, K. Hsu et al., Impacts of oxygen vacancies on zinc ion intercalation in $\mathrm{VO}_{2}$. ACS Nano 14(5), 5581-5589 (2020). https://doi.org/10.1021/acsnano.9b09963

25. B. He, Q. Zhang, P. Man, Z. Zhou, C. Li et al., Self-sacrificed synthesis of conductive vanadium-based metal-organic framework nanowire-bundle arrays as binder-free cathodes for high-rate and high-energy-density wearable $\mathrm{Zn}$-ion batteries. Nano Energy 64, 103935 (2019). https://doi.org/10.1016/j. nanoen.2019.103935

26. L. Ma, S. Chen, C. Long, X. Li, Y. Zhao et al., Achieving highvoltage and high-capacity aqueous rechargeable zinc ion battery by incorporating two-species redox reaction. Adv. Energy Mater. 9(45), 1902446 (2019). https://doi.org/10.1002/aenm. 201902446

27. P. He, M. Yan, G. Zhang, R. Sun, L. Chen et al., Layered VS nanosheet-based aqueous $\mathrm{Zn}$ ion battery cathode. Adv. Energy Mater. 7(11), 1601920 (2017). https://doi.org/10.1002/aenm. 201601920

28. C. Han, T. Zhang, J. Li, B. Li, Z. Lin, Enabling flexible solidstate $\mathrm{zn}$ batteries via tailoring sulfur deficiency in bimetallic sulfide nanotube arrays. Nano Energy 77, 105165 (2020). https://doi.org/10.1016/j.nanoen.2020.105165

29. H. Yao, Q. Li, M. Zhang, Z. Tao, Y. Yang, Prolonging the cycle life of zinc-ion battery by introduction of $\left[\mathrm{Fe}(\mathrm{CN})_{6}\right]^{4-}$ to pani via a simple and scalable synthetic method. Chem. Eng. J. 392, 123653 (2020). https://doi.org/10.1016/j.cej.2019.123653

30. K. Zhu, T. Wu, S. Sun, W. van den Bergh, M. Stefik et al., Synergistic $\mathrm{H}^{+} / \mathrm{Zn}^{2+}$ dual ion insertion mechanism in highcapacity and ultra-stable hydrated $\mathrm{VO}_{2}$ cathode for aqueous Zn-ion batteries. Energy Storage Mater. 29, 60-70 (2020). https://doi.org/10.1016/j.ensm.2020.03.030

31. N. Zhang, M. Jia, Y. Dong, Y. Wang, J. Xu et al., Hydrated layered vanadium oxide as a highly reversible cathode for rechargeable aqueous zinc batteries. Adv. Funct. Mater. 29(10), 1807331 (2019). https://doi.org/10.1002/adfm.20180 7331

32. S. Chen, Y. Zhang, H. Geng, Y. Yang, X. Rui et al., Zinc ions pillared vanadate cathodes by chemical pre-intercalation towards long cycling life and low-temperature zinc ion batteries. J. Power Sources 441, 227192 (2019). https://doi.org/10. 1016/j.jpowsour.2019.227192

33. F. Wan, Z. Niu, Design strategies for vanadium-based aqueous zinc-ion batteries. Angew. Chem. Int. Ed. 58(46), 1635816367 (2019). https://doi.org/10.1002/anie.201903941

34. M. Liu, B. Su, Y. Tang, X. Jiang, A. Yu, Recent advances in nanostructured vanadium oxides and composites for energy conversion. Adv. Energy Mater. 7(23), 1700885 (2017). https://doi.org/10.1002/aenm.201700885

35. Y. Zhang, F. Wan, S. Huang, S. Wang, Z. Niu et al., A chemically self-charging aqueous zinc-ion battery. Nat. Commun. 11(1), 2199 (2020). https://doi.org/10.1038/ s41467-020-16039-5

36. D. Chen, X. Rui, Q. Zhang, H. Geng, L. Gan et al., Persistent zinc-ion storage in mass-produced $\mathrm{V}_{2} \mathrm{O}_{5}$ architectures. Nano Energy 60, 171-178 (2019). https://doi.org/10.1016/j.nanoen. 2019.03.034

37. H. Liu, W. Yang, Ultralong single crystalline $\mathrm{V}_{2} \mathrm{O}_{5}$ nanowire/graphene composite fabricated by a facile green approach and its lithium storage behavior. Energy Environ. Sci. 4(10), 4000-4008 (2011). https://doi.org/10.1039/c1ee01353j 
38. L. Xing, K. Han, Q. Liu, Z. Liu, J. Chu et al., Hierarchical two-atom-layered $\mathrm{WSe}_{2} / \mathrm{C}$ ultrathin crumpled nanosheets assemblies: Engineering the interlayer spacing boosts potassium-ion storage. Energy Storage Mater. 36, 309-317 (2021). https://doi.org/10.1016/j.ensm.2021.01.005

39. L. Zhang, W. Wang, S. Lu, Y. Xiang, Carbon anode materials: A detailed comparison between na-ion and k-ion batteries. Adv. Energy Mater. 11, 2003640 (2021). https://doi.org/10. 1002/aenm.202003640

40. W. Wang, H. Huang, B. Wang, C. Qian, P. Li et al., A new dual-ion battery based on amorphous carbon. Sci. Bull. 64(21), 1634-1642 (2019). https://doi.org/10.1016/j.scib. 2019.08.021

41. P. He, G. Zhang, X. Liao, M. Yan, X. Xu et al., Sodium ion stabilized vanadium oxide nanowire cathode for high-performance zinc-ion batteries. Adv. Energy Mater. 8(10), 1702463 (2018). https://doi.org/10.1002/aenm.201702463

42. S. Islam, M.H. Alfaruqi, D.Y. Putro, V. Soundharrajan, B. Sambandam et al., $\mathrm{K}^{+}$intercalated $\mathrm{V}_{2} \mathrm{O}_{5}$ nanorods with exposed facets as advanced cathodes for high energy and high rate zinc-ion batteries. J. Mater. Chem. A 7(35), 20335-20347 (2019). https://doi.org/10.1039/c9ta05767f

43. Y. Yang, Y. Tang, S. Liang, Z. Wu, G. Fang et al., Transition metal ion-preintercalated $\mathrm{V}_{2} \mathrm{O}_{5}$ as high-performance aqueous zinc-ion battery cathode with broad temperature adaptability. Nano Energy 61, 617-625 (2019). https://doi.org/10.1016/j. nanoen.2019.05.005

44. M. Yan, P. He, Y. Chen, S. Wang, Q. Wei et al., Water-lubricated intercalation in $\mathrm{V}_{2} \mathrm{O}_{5} \cdot \mathrm{nH}_{2} \mathrm{O}$ for high-capacity and highrate aqueous rechargeable zinc batteries. Adv. Mater. 30(1), 1703725 (2018). https://doi.org/10.1002/adma.201703725

45. S. Liu, H. Zhu, B. Zhang, G. Li, H. Zhu et al., Tuning the kinetics of zinc-ion insertion/extraction in $\mathrm{V}_{2} \mathrm{O}_{5}$ by in situ polyaniline intercalation enables improved aqueous zinc-ion storage performance. Adv. Mater. 32(26), 2001113 (2020). https://doi.org/10.1002/adma.202001113

46. Q. Li, X. Rui, D. Chen, Y. Feng, N. Xiao et al., A highcapacity ammonium vanadate cathode for zinc-ion battery. Nano-Micro Lett. 12, 67 (2020). https://doi.org/10.1007/ s40820-020-0401-y

47. H. Jiang, Y. Zhang, Y. Liu, J. Yang, L. Xu et al., In situ grown $2 \mathrm{D}$ hydrated ammonium vanadate nanosheets on carbon cloth as a free-standing cathode for high-performance rechargeable Zn-ion batteries. J. Mater. Chem. A 8(30), 15130-15139 (2020). https://doi.org/10.1039/d0ta05065b

48. X. Wang, B. Xi, Z. Feng, W. Chen, H. Li et al., Layered (NH4)2V6O16 1.5H2O nanobelts as a high-performance cathode for aqueous zinc-ion batteries. J. Mater. Chem. A 7(32), 19130-19139 (2019). https://doi.org/10.1039/c9ta05922a

49. D. Bin, Y. Liu, B. Yang, J. Huang, X. Dong et al., Engineering a high-energy-density and long lifespan aqueous zinc battery via ammonium vanadium bronze. ACS Appl. Mater. Interfaces 11(23), 20796-20803 (2019). https://doi.org/10.1021/acsami. $9 \mathrm{~b} 03159$

50. G. Yang, T. Wei, C. Wang, Self-healing lamellar structure boosts highly stable zinc-storage property of bilayered vanadium oxides. ACS Appl. Mater. Interfaces 10(41), 35079_ 35089 (2018). https://doi.org/10.1021/acsami.8b10849

51. Y. Zhang, H. Jiang, L. Xu, Z. Gao, C. Meng, Ammonium vanadium oxide $\left[\left(\mathrm{NH}_{4}\right)_{2} \mathrm{~V}_{4} \mathrm{O}_{9}\right]$ sheets for high capacity electrodes in aqueous zinc ion batteries. ACS Appl. Energy Mater. 2(11), 7861-7869 (2019). https://doi.org/10.1021/acsaem. 9b01299

52. B. Tang, J. Zhou, G. Fang, F. Liu, C. Zhu et al., Engineering the interplanar spacing of ammonium vanadates as a high-performance aqueous zinc-ion battery cathode. J. Mater. Chem. A 7(3), 940-945 (2019). https://doi.org/10.1039/c8ta09338e

53. E.A. Esparcia, M.S. Chae, J.D. Ocon, S.-T. Hong, Ammonium vanadium bronze $\left(\mathrm{NH}_{4} \mathrm{~V}_{4} \mathrm{O}_{10}\right)$ as a high-capacity cathode material for nonaqueous magnesium-ion batteries. Chem. Mater. 30(11), 3690-3696 (2018). https://doi.org/10.1021/acs. chemmater.8b00462

54. Y. Xu, H. Dong, M. Zhou, C. Zhang, Y. Wu et al., Ammonium vanadium bronze as a potassium-ion battery cathode with high rate capability and cyclability. Small Methods 3(8), 1800349 (2019). https://doi.org/10.1002/smtd.201800349

55. X. Chen, L. Wang, H. Li, F. Cheng, J. Chen, Porous $\mathrm{V}_{2} \mathrm{O}_{5}$ nanofibers as cathode materials for rechargeable aqueous zincion batteries. J. Energy Chem. 38, 20-25 (2019). https://doi. org/10.1016/j.jechem.2018.12.023

56. X. Wu, Y. Tao, L. Dong, J. Hong, Synthesis and characterization of self-assembling $(\mathrm{NH} 4)_{0.5} \mathrm{~V}_{2} \mathrm{O}_{5}$ nanowires. J. Mater. Chem. 14(5), 901-904 (2004). https://doi.org/10.1039/b3147 $75 \mathrm{~d}$

57. D. Fang, Y. Cao, R. Liu, W. Xu, S. Liu et al., Novel hierarchical three-dimensional ammonium vanadate nanowires electrodes for lithium ion battery. Appl. Surf. Sci. 360, 658-665 (2016). https://doi.org/10.1016/j.apsusc.2015.11.038

58. T.-Z. Ren, Z.-Y. Yuan, X. Zou, Crystal growth of mixedvalence ammonium vanadates. Cryst. Res. Technol. 42(4), 317-320 (2007). https://doi.org/10.1002/crat.200610821

59. H. Wang, K. Huang, C. Huang, S. Liu, Y. Ren et al., (NH4)05V2O5 nanobelt with good cycling stability as cathode material for Li-ion battery. J. Power Sources 196(13), 5645-5650 (2011). https://doi.org/10.1016/j.jpowsour.2011. 02.046

60. S.H. Lee, J.M. Koo, S.G. Oh, S.S. Im, Facile synthesis of ammonium vanadate nanofibers by using reflux in aqueous $\mathrm{V}_{2} \mathrm{O}_{5}$ solution with ammonium persulfate. Mater. Chem. Phys. 194, 313-321 (2017). https://doi.org/10.1016/j.matchemphys. 2017.03.053

61. A. Sarkar, S. Sarkar, T. Sarkar, P. Kumar, M.D. Bharadwaj et al., Rechargeable sodium-ion battery: High-capacity ammonium vanadate cathode with enhanced stability at high rate. ACS Appl. Mater. Interfaces 7(31), 17044-17053 (2015). https://doi.org/10.1021/acsami.5b03210

62. T. Wei, Y. Liu, G. Yang, C. Wang, Aluminum vanadate hollow spheres as zero-strain cathode material for highly reversible and durable aqueous zinc-ion batteries. Energy Storage Mater. 30, 130-137 (2020). https://doi.org/10.1016/j.ensm.2020.04. 039 
63. T. Sarkar, P. Kumar, M.D. Bharadwaj, U. Waghmare, Structural transformation during $\mathrm{Li} / \mathrm{Na}$ insertion and theoretical cyclic voltammetry of the $\delta-\mathrm{NH}_{4} \mathrm{~V}_{4} \mathrm{O}_{10}$ electrode: A firstprinciples study. Phys. Chem. Chem. Phys. 18(14), 9344-9348 (2016). https://doi.org/10.1039/c5cp07782f

64. J. Zhou, L. Shan, Z. Wu, X. Guo, G. Fang et al., Investigation of $\mathrm{V}_{2} \mathrm{O}_{5}$ as a low-cost rechargeable aqueous zinc ion battery cathode. Chem. Commun. 54(35), 4457-4460 (2018). https:// doi.org/10.1039/c8cc02250j

65. S. Deng, Z. Yuan, Z. Tie, C. Wang, L. Song et al., Electrochemically induced metal-organic-framework-derived amorphous $\mathrm{V}_{2} \mathrm{O}_{5}$ for superior rate aqueous zinc-ion batteries. Angew. Chem. Int. Ed. 59(49), 22002-22006 (2020). https:// doi.org/10.1002/ange.202010287

66. N. Liu, X. Wu, L. Fan, S. Gong, Z. Guo et al., Intercalation pseudocapacitive $\mathrm{Zn}^{2+}$ storage with hydrated vanadium dioxide toward ultrahigh rate performance. Adv. Mater. 32(42), 1908420 (2020). https://doi.org/10.1002/adma.201908420

67. H.S. Kim, J.B. Cook, H. Lin, J.S. Ko, S.H. Tolbert et al., Oxygen vacancies enhance pseudocapacitive charge storage properties of $\mathrm{MoO}_{3-\mathrm{x}}$. Nat. Mater. 16(4), 454-460 (2017). https:// doi.org/10.1038/nmat4810

68. W. Xu, C. Sun, N. Wang, X. Liao, K. Zhao et al., Sn stabilized pyrovanadate structure rearrangement for zinc ion battery. Nano Energy 81, 105584 (2021). https://doi.org/10.1016/j. nanoen.2020.105584

69. Y. Shi, J.Z. Wang, S.L. Chou, D. Wexler, H.J. Li et al., Hollow structured $\mathrm{Li}_{3} \mathrm{VO}_{4}$ wrapped with graphene nanosheets in situ prepared by a one-pot template-free method as an anode for lithium-ion batteries. Nano Lett. 13(10), 4715-4720 (2013). https://doi.org/10.1021/n1402237u

70. P. Hu, T. Zhu, X. Wang, X. Wei, M. Yan et al., Highly durable $\mathrm{Na}_{2} \mathrm{~V}_{6} \mathrm{O}_{16} \cdot 1.63 \mathrm{H}_{2} \mathrm{O}$ nanowire cathode for aqueous zinc-ion battery. Nano Lett. 18(3), 1758-1763 (2018). https://doi.org/ 10.1021/acs.nanolett.7b04889

71. H. Jiang, Y. Zhang, Z. Pan, L. Xu, J. Zheng et al., NH4V3O8.0@5H2O nanobelts with intercalated water molecules as a high performance zinc ion battery cathode. Mater. Chem. Front. 4(5), 1434-1443 (2020). https://doi.org/10.1039/ d0qm00051e

72. Z. Hou, M. Dong, Y. Xiong, X. Zhang, H. Ao et al., A highenergy and long-life aqueous $\mathrm{Zn} /$ Birnessite battery via reversible water and $\mathrm{Zn}^{2+}$ coinsertion. Small 16(26), 2001228 (2020). https://doi.org/10.1002/smll.202001228

73. H. Qin, L. Chen, L. Wang, X. Chen, Z. Yang, $\mathrm{V}_{2} \mathrm{O}_{5}$ hollow spheres as high rate and long life cathode for aqueous rechargeable zinc ion batteries. Electrochim. Acta 306, 307316 (2019). https://doi.org/10.1016/j.electacta.2019.03.087
74. C. Xia, J. Guo, P. Li, X. Zhang, H.N. Alshareef, Highly stable aqueous zinc-ion storage using a layered calcium vanadium oxide bronze cathode. Angew. Chem. Int. Ed. 57(15), 3943 3948 (2018). https://doi.org/10.1002/anie.201713291

75. M. Wang, J. Zhang, L. Zhang, J. Li, W. Wang et al., Graphenelike vanadium oxygen hydrate $(\mathrm{VOH})$ nanosheets intercalated and exfoliated by polyaniline (PANI) for aqueous zinc-ion batteries (ZIBs). ACS Appl. Mater. Interfaces 12(28), 31564 31574 (2020). https://doi.org/10.1021/acsami.0c10183

76. B. Tang, G. Fang, J. Zhou, L. Wang, Y. Lei et al., Potassium vanadates with stable structure and fast ion diffusion channel as cathode for rechargeable aqueous zinc-ion batteries. Nano Energy 51, 579-587 (2018). https://doi.org/10.1016/j.nanoen. 2018.07.014

77. Z. Cao, P. Zhuang, X. Zhang, M. Ye, J. Shen et al., Strategies for dendrite-free anode in aqueous rechargeable zinc ion batteries. Adv. Energy Mater. 10(30), 2001599 (2020). https:// doi.org/10.1002/aenm.202001599

78. F. Wan, L. Zhang, X. Dai, X. Wang, Z. Niu et al., Aqueous rechargeable zinc/sodium vanadate batteries with enhanced performance from simultaneous insertion of dual carriers. Nat. Commun. 9(1), 1656 (2018). https://doi.org/10.1038/ s41467-018-04060-8

79. N. Wang, C. Sun, X. Liao, Y. Yuan, H. Cheng et al., Reversible (de)intercalation of hydrated $\mathrm{Zn}^{2+}$ in $\mathrm{Mg}^{2+}$-stabilized $\mathrm{V}_{2} \mathrm{O}_{5}$ nanobelts with high areal capacity. Adv. Energy Mater. 10(41), 2002293 (2020). https://doi.org/10.1002/aenm.202002293

80. D. Yu, Z. Wei, X. Zhang, Y. Zeng, C. Wang et al., Boosting $\mathrm{Zn}^{2+}$ and $\mathrm{NH}_{4}{ }^{+}$storage in aqueous media via in-situ electrochemical induced $\mathrm{VS}_{2} / \mathrm{VO}_{\mathrm{x}}$ heterostructures. Adv. Funct. Mater. 31, 2008743 (2020). https://doi.org/10.1002/adfm. 202008743

81. J. Ji, H. Wan, B. Zhang, C. Wang, Y. Gan et al., $\mathrm{Co}^{2+/ 3+/ 4+}$-regulated electron state of $\mathrm{Mn}-\mathrm{O}$ for superb aqueous zinc-manganese oxide batteries. Adv. Energy Mater. 11(6), 2003203 (2020). https://doi.org/10.1002/aenm.202003203

82. F. Liu, Z. Chen, G. Fang, Z. Wang, Y. Cai et al., $\mathrm{V}_{2} \mathrm{O}_{5}$ nanospheres with mixed vanadium valences as high electrochemically active aqueous zinc-ion battery cathode. Nano-Micro Lett. 11, 25 (2019). https://doi.org/10.1007/ s40820-019-0256-2

83. Y. Yang, J. Xiao, J. Cai, G. Wang, W. Du et al., Mixed-valence copper selenide as an anode for ultralong lifespan rockingchair Zn-ion batteries: An insight into its intercalation/extraction kinetics and charge storage mechanism. Adv. Funct. Mater. 31(3), 2005092 (2020). https://doi.org/10.1002/adfm. 202005092 